Document downloaded from:

http://hdl.handle.net/10251/39803

This paper must be cited as:

Macian Martinez, V.; Serrano Cruz, JR.; Dolz Ruiz, V.; Sánchez Serrano, J. (2013).

Methodology to design a bottoming Rankine cycle, as a waste energy recovering system in vehicles. Study in a HDD engine. Applied Energy. 104:758-771.

doi:10.1016/j.apenergy.2012.11.075.

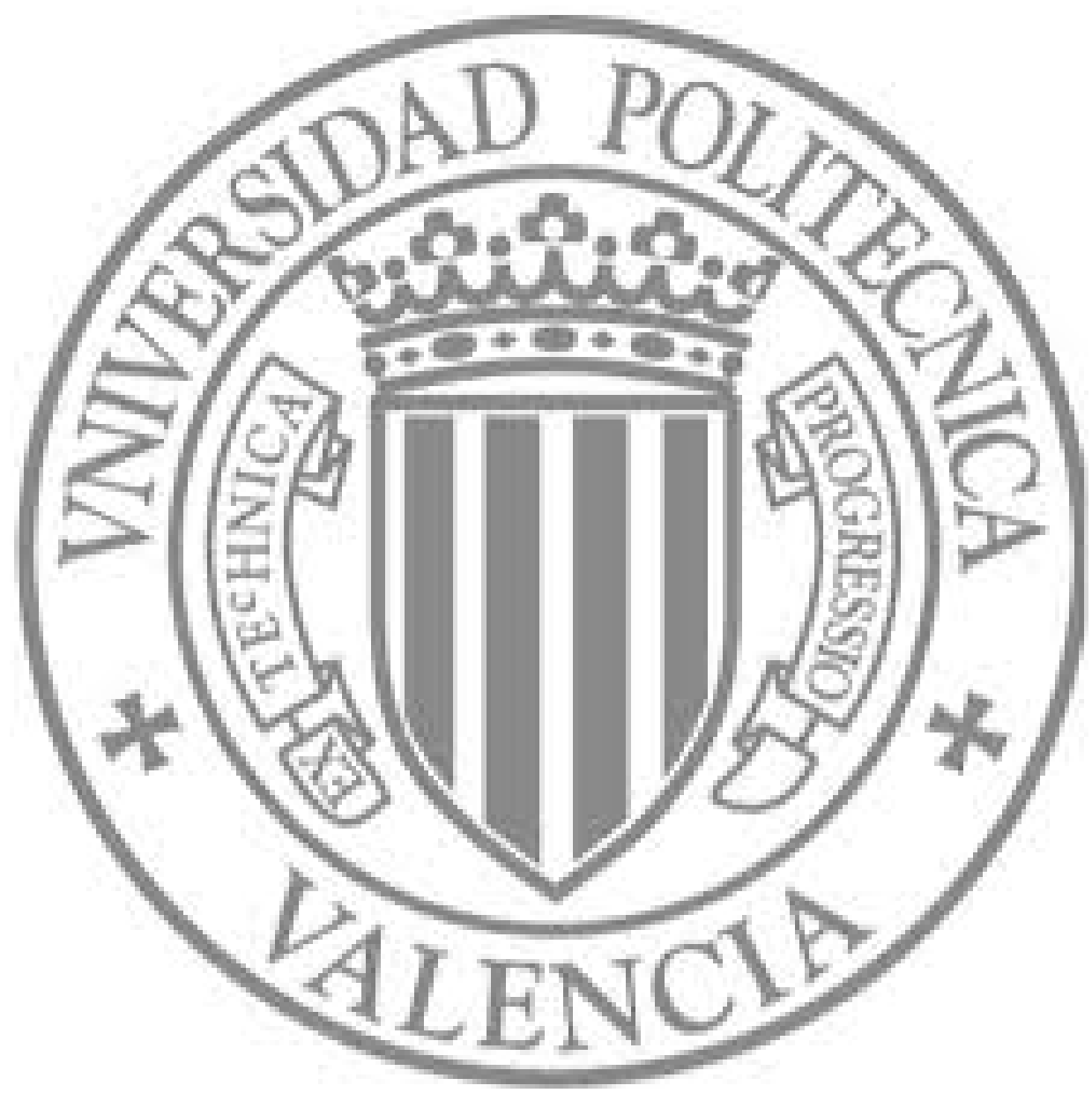

The final publication is available at

http://dx.doi.org/10.1016/j.apenergy.2012.11.075

Copyright Elsevier 


\title{
Methodology to design a bottoming Rankine cycle, as a waste energy recovering system in vehicles. Study in a HDD engine
}

\author{
V. Macián, J. R. Serrano, V. Dolz, J. Sánchez \\ Universitat Politècnica de València, CMT-Motores Térmicos, Camino de Vera s/n, 46022 Valencia, Spain.
}

\begin{abstract}
This article describes a methodology for the optimization of a bottoming cycle as a waste heat recovering system in vehicles. The methodology is applied to two particular cases in order to evaluate the preliminary energetic and technical feasibility of the implementation of a bottoming cycle in a heavy duty diesel (HDD) engine considering two different criteria. Initially, a study of the different waste heat sources of the engine is described. In this study, the power and exergy of each heat source is quantified, in order to evaluate which sources are suitable to be used in the bottoming cycle. The optimum working fluids to run the cycles are selected (water and R245fa). Then, the ideal Rankine cycle is optimized for the two different working fluids and different sets of heat sources (all the available heat sources and the sources with high exergy respectively) throughout the engine operating range, reaching a maximum improvement of $15 \%$ of the fuel consumption of the engine. Later, a study of the minimum temperature difference between the hot and cold flow of the heat exchangers is described. The improvements in fuel consumption and the size of the installed heat exchanger are related to this temperature difference. Finally, the non-ideal behavior of the machines (pump and expander) is analyzed, obtaining a maximum improvement of $10 \%$ in brake specific fuel consumption (bsfc).

Keywords: Organic Rankine Cycle, Diesel, Rankine Cycle, Recover Waste Power
\end{abstract}

\section{Introduction}

The interest for increasing fuel economy and efficiency has recently been growing among governments, industrial companies and engine manufactures to the extent that the quantity of waste energy produced [1], represent a driving force for development of more effective methods of waste energy recovery [2]. The carbon dioxide emissions are also gaining significant attention due to its association with global warming and the fact that about $80 \%$ of said emissions 6 in the Organization for Economic Co-operation and Development (OECD) countries or the European Union are due to the use and production of energy, industries or manufacturing [3, 4]. Nowadays, the global carbon dioxide emissions have risen steadily over the past 50 years to a concentration of approximately $380 \mathrm{ppm}$ in the atmosphere as of 2006 [5].

\footnotetext{
*V. Dolz. CMT-Motores Térmicos,Universitat Politècnica de València, Camino de Vera s/n, 46022 Valencia, Spain. Phone: +34963877650 Fax: +34963877659 e-mail: vidolrui@mot.upv.es
} 
A large number of solutions have been proposed to generate electricity from low temperature waste heat sources and are now applied to such diversified fields as solar thermal power, geothermal, biomass and industrial waste heat. Among the proposed solutions, the implementation of a bottoming cycle currently is one of the most studied options $[6,7]$. Among the different solutions, Rankine Cycle (RC), Organic Rankine Cycle (ORC), Stirling cycle (SC) and the Brayton Cycle (BC) can be analyzed in order to find the one generating the largest power. The RC and ORC solution is considered by Bianchi et al. [8] as the more profitable configuration for converting the low-grade power into the higher output power. Many theoretical investigations have been performed in order to design the optimum cycle (working fluid, evaporator and condenser pressure, superheating temperature, choise of the expander, etc.) taking into account the heat source characteristics [9-15].

One of the largest sources of waste energy is the internal combustion (IC) engine used in different vehicles (naval ship, railway, automotive, etc) as shown in the Eurostat publication in 2011 [16]. The IC engine converts approximately one third of the combustion power into mechanical power. The remaining power is distributed to different heat exchangers or is directly released to the ambient (exhaust gases). As a result, an IC presents various waste heat sources with a wide range of temperature and exergy levels [17-19]. Additionally, the waste heat sources vary considerably depending on the engine operating point [20]. Therefore, the preliminary design of the optimal solution is usually not an easy task $[21,22]$. Therefore, the published articles on this topic focus on different factors about this complex problem. In this paper, the problem of designing a bottoming cycle to recover the energy of waste heat sources in an IC engine is addressed generally. Consequently, this work considers all these partial issues studied in other articles as parts, integrating them in a general methodology and considering the influence of these partial topics in the obtained final result.

The methodology discussed in this paper is a comprehensive theoretical study for simplifying the complex problem of the waste heat source recovery system in vehicles. This methodology implies the evaluation of all the heat sources at each operating points and selection of the waste heat sources. It then applies an iterative-parametric optimization procedure in order to calculate the optimum working fluid and cycle conditions based on the maximum power output cycle for each operating points taking into account various restrictions as space requirements limitations, maximum expansion ratio etc,. The methodology is also applied to a bottoming cycle for a Heavy Duty Diesel (HDD) engine with a two-stage turbocharging system, from which experimental data are available. The resulting power balance was used to propose an optimal configuration for the most frequent combinations of speed and load engine conditions (operating engine points) [23]. The goal of this paper is to develop a general theoretical methodology in order to evaluate the maximum power and sizing of the system (energetic and technical feasibility) of the different configurations and show valuable results for the remaining problem of the waste heat power recovery in IC engines. 


\section{Methodology}

The design of the implementation of a heat power recovery system in a vehicle is complex due to numerous restrictions (maximum pressure ratio in the expander, condensation temperature, minimum temperature difference between hot and cold source, etc) or goals (reduction of fuel consumption, maximum output power, space limitations, etc) that must be considered. Sometimes the selection of the waste heat sources in a bottoming cycle for a vehicle constitutes the key part of the design process. Two important criteria are associated with this selection: the power output and the space requirements of the cycle. The more wasted heat to recover, the higher the power output and heat exchanger volume. Once the waste heat sources are selected, the design calculations are essentially a series of iterative calculations made on the preliminary design until a satisfactory solution is achieved. In these calculations, different working fluids, the effect of the different irreversibilities and other additional restrictions are considered in order to define a preliminary design of the heat recovery system.

In this section, a methodology is proposed in order to simplify the process of the selection of the best configuration of a bottoming cycle by taking into account different initial limitations and goals. The proposed methodology consists of the following steps, also shown in Figure 1:

1. Specification of the problem. In this first step, the goals and limits of the bottoming cycle are fixed. The goals must be satisfied by all the steps followed in the methodology. The limits must be imposed in the cycle in order to obtain the cycle output power.

2. Evaluation of all the waste heat sources, in order to identify the sources with higher heat power level and better recoverability, using energetic and exergetic studies.

3. Selection of the waste heat sources. The most suitable heat sources are selected depending on their exergetic qualities, in order to use the best heat sources in the next studies. In this step, the available heat power in the selected sources must be higher than the minimum power output objective. If the total waste heat power is less than this requirement, the design problem has no solution. However, fewer heat sources used in the process imply more compact heat exchangers in the cycle, a less complex control of the cycle and it can produce a higher efficiency.

4. Selection of the working fluid. Several working fluids commonly used in bottoming cycles are considered in order to define those which produce the maximum cycle output power in the following step.

5. Calculation with the ideal cycle assumption. The working fluid selected and the limits detailed in the first step are imposed in order to evaluate the ideal configuration for each operating point. Isentropic compression and expansion processes and zero pressure drops in tubes are imposed in this ideal study. If the power output obtained in the solution does not satisfy the power specification, the working fluid and/or heat sources selected will have to be reconsidered. If not, the design problem has no solution.

6. Sizing of heat exchangers. The size of the heat exchanger in the optimum ideal cycle configuration is calculated through the heat transfer needed, the pressure drop allowed and the minimum temperature difference between 
the working fluid and the engine waste heat sources $(d T)$. The heat exchanger volume must satisfy the space requirement imposed. The $d T$ must be reconsidered when the heat exchanger volume does not satisfy the volume requirement.

7. Calculation of the real cycle. Non-isentropic compression and expansion processes are calculated in this point of the theoretical study. Different charts are used to estimate the pump and expander machine efficiencies [24, 25]. If the power output obtained in this step is lower than the minimum power required, the selection of working fluid and/or heat sources will have to be reconsidered. In this step, the effect of the real cycle assumption on the heat exchanger sizing is neglected.

8. Other pre-imposed limits and goals must be evaluated before determining the final optimum configuration. In this last step, other feasibility criteria such as: maximum installation cost or weight could be evaluated before determining the optimal bottoming cycle configuration.

Following, two examples are shown in next section in order to illustrate the effect of each step on the performance of a bottoming cycle for a double-stage HDD engine.

\section{Application of the methodology for bottoming cycle in HDD engine}

Recovering waste energy in an automotive is one of the most complex cases in the implementation of a bottoming cycle in vehicles due to four main aspects: 1) There are many operating points, 2) in each operating point there are different available waste heat sources, 3) these sources present very different temperature levels and power available, 4) the limitation and goals are usually very strict because the solution implemented must be cheap, without large space and weight requirement, technically feasible and profitable in global energetic terms. In this section, the problem of the implementation of a bottoming cycle in HDD Engine is selected for the purpose of illustrating the methodology detailed previously.

\subsection{Problem specification}

In a vehicle, the reduction of bsfc (brake specific fuel consumption) can be considered as the most important goal of the implementation of this kind of technology. A high power output in a bottoming cycle implies an important heat transfer process. This heat transfer process requires different heat exchangers whose volume and weight requirements can be higher than allowed by the vehicle design limits. Taking this restriction into account, the methodology was applied following two different goals as examples:

- Maximum reduction of brake specific fuel consumption $(b s f c)$ without any space limitation, here in after, case A.

- Acceptable reduction of $b s f c$ with the space restriction, here in after, case $\mathbf{B}$. In this work, a $b s f c$ higher than 5 $\%$ and space requirement lower than $0.2 \mathrm{~m}^{3}$ were imposed. The imposed goals or restrictions strongly depend on the engine manufacturing criteria. 
The limits of the problems were fixed as:

- The pressure ratio in the expansion machine must be lower than 25 to achieve an efficient expansion process.

- Initially, the proposal cycles minimum temperature difference in the heat exchange processes is fixed to $10^{\circ} \mathrm{C}$ [26-28].

- The working fluid in the condenser had to be cooled by the ambient. These conditions were fixed in $40^{\circ} \mathrm{C}$ and 1 bar.

The engine used in this study was a 12 litre double-stage turbocharged HDD [29]. The maximum engine torque is $2100 \mathrm{Nm}$ and this values is achieved at $1000 \mathrm{rpm}$ and $100 \%$ load and the maximum engine power is $311 \mathrm{kw}$ at 1800 and $100 \%$ load. The HDD has been adapted according to the anti-pollution directive (US2007) [23].The scheme of the engine is shown in Figure 2.

The engine is placed in a test bench with an electric brake which allows steady tests under different operational conditions. The engine is also instrumented to measure torque, engine speed, fuel consumption, air mass flow in the intake line, pressures and temperatures in the compressors and turbines. The blow-by effect is neglected, for this, the exhaust gases mass flow is calculated as the sum of intake mass flow and fuel consumption flow. The waste power of the exhaust gases is calculated using the measured temperature and the estimated mass flow. The waste power of the remaining heat sources have been calculated measuring the inlet and outlet temperatures and coolant mass flow in the cylinders (radiator) and the rest of heat exchangers (EGR cooler, intercooler and aftercooler).

Eleven steady operating points of the engine have been chosen for testing and there after, to design and simulate the recovery cycle. These points represent the steady-state engine test modes with defined speed and load used by the directive (US2007) for the evaluation of the emission [23]. Table 1 lists these operational points.

\subsection{Evaluation of the heat sources}

Analyzing the wasted power in the thermal engine to identify the main waste heat sources is the second step of this methodology. These sources are located in: 1) the exhaust gases 2) the EGR coolers, 3) the intercooler, 4) the aftercooler and 5) the engine cooling water. The heat power in these sources is calculated using mass flow and temperature measurements. The available power between the inlet and outlet conditions ( 1 and 2 ) of each source is calculated considering the gases as ideal and perfect gases, Equation (1):

$$
E_{\text {flow }}=\dot{m}_{\text {flow }}\left(h_{1}-h_{2}\right)=\dot{m}_{\text {flow }} C_{p}\left(T_{1}-T_{2}\right)
$$

where $C_{p}$ has been considerate $1 \mathrm{~kJ} / \mathrm{kgK}$ and $1.15 \mathrm{~kJ} / \mathrm{kgK}$ for fresh air and combustion gases respectively. The ambient conditions are considered as the reference state.

The energetic levels of the waste heat sources for two different engine operative points are listed in Table 2: 1800 rpm-100\% load and $1200 \mathrm{rpm}-25 \%$. These points were selected for two reasons: 1) They are points with energetic 
level distributions very different and 2) The maximum reduction of brake specific fuel consumption will be achieved in these operative points for the two cycles studied in this paper. The total waste power of the engine (summarizing all the heat sources) is represented in the engine map (Figure 3). The contour lines in Figure 3 were created on the basis of the eleven engine operating points. The Kriging interpolation method [30] was applied on all contour lines of the figures in the paper using a surface mapping software (SURFACE v8.0) [31]. Figure 3 shows that the available power increases with the crankshaft speed and the engine load. The highest waste heat power corresponds to the $1800 \mathrm{rpm}$ and $100 \%$ load, because this is the point where the most fuel is injected. While $600 \mathrm{rpm}$ and $0 \%$ does not practically generate any waste heat.

The waste heat power of the HDD engine is up to $420 \mathrm{~kW}$. But this power can be used to improve the engine efficiency if it is converted into mechanical work. The exergetic study of these waste heat sources can evaluate which is the maximum obtainable work in each engine operating point. The exergy represents the maximum work that can be extracted from a thermodynamic cycle from an initial state (state 1) to an environment state (state 0 ). Thus, the exergy is obtained as Equation (2) shows:

$$
E x_{\text {flow }}=\dot{m}_{\text {flow }}\left(\left(h_{1}-h_{0}\right)-T_{0}\left(s_{1}-s_{0}\right)\right)
$$

In this way, the exergy variation between two states (from 1 to 2) with the same environmental conditions can be obtained as Equation (3) shows:

$$
\Delta E x_{\text {flow } w_{1-2}}=\dot{m}_{\text {flow }}\left(\left(h_{2}-h_{1}\right)-T_{0}\left(s_{2}-s_{1}\right)\right)
$$

The exergies of the waste heat sources considered in this study can be calculated as a total exergy (exhaust gases) using Equation (2) or as variation of exergy (intercooler, aftercooler, EGR and cooling water) using Equation (3). The exergetic levels of the waste heat sources at $1800 \mathrm{rpm}-100 \%$ load and $1200 \mathrm{rpm}$ and $25 \%$ load are listed in Table 2 Adding all these wasted exergies, the total waste exergy can be calculated. Figure 4 shows this total waste exergy on the engine map.

When the results are analyzed in terms of exergy, we can state that a third of the total waste power could be converted into mechanical power by a thermodynamic cycle, if the external and internal irreversibilities are not considered.

It is worth noting that in a thermodynamic cycle, the highest exergy destruction will further mainly take place during the heat transfer process in the heat exchangers. The greater the temperature difference between the cooled fluid and the heated fluid, the greater the exergy destruction [32-35]. On the other hand, this temperature difference will depend strongly on the selected working fluid

\subsection{Selection of the waste heat sources}

The third step is the selection of the waste heat sources. The selection process depends on the goals and limitations fixed in the specification problem (first step). To illustrate the methodology exposed in this paper, two different 
selections of the heat sources will be carried out the $\mathbf{A}$ and $\mathbf{B}$ problem criteria. Each waste heat source in a HDD engine has a different temperature, exergetic and energetic level. These differences can produce significant variations in the cycle efficiency and consequently in the cycle net power [21,22]. The variations in the cycle efficiency occur because the temperature of the heat source determines the evaporator temperature of the cycle and the evaporator temperature is directly related to the cycle efficiency. The exergy contribution of each waste heat source has been studied to select the best sources in the engine (generally those sources with highest temperature), in order to address step (2) of the proposed methodology in Figure 1. The exergy contribution of EGR, exhaust gases and aftercooler is shown in Figure 5. These three heat sources account for nearly $80 \%$ of the total exergy in the engine. Thus, the implementation of a bottoming cycle with these waste heat sources is highly recommended in order to simplify the bottoming cycle structure.

Two different sets of heat sources have been considered in this study: The first configuration for the case $\mathbf{A}$ includes all the HDD Engine waste heat sources, in order to evaluate the maximum output power obtained at each engine working condition. The second option for the case $\mathbf{B}$, considers only the three higher exergetic sources (exhaust gases, EGR and aftercooler).

\subsection{Selection of the working fluid}

One of the factors regarding the efficiency of a bottoming cycle is the selection of the optimum working fluid $[36,37]$. For this study, different fluids like halocarbons, CFC, HCFC, HFC, Hydrocarbons, ammonia and water have been considered as possible working fluids. These fluids were analyzed in previous works with the same HDD engine studied in this paper for different bottoming cycles by Dolz et al. [21] and Serrano et al. [22]. The criteria used for the selection of the working fluid are good physical and thermodynamic characteristics providing high thermal efficiency and high exploitation of the available heat source. Furthermore, the selected fluid should be environmentally friendly, present low toxicity and characteristics of low-zero inflammability. In these works, water and R245fa were considered as the optimum working fluids.

A RC with water as working fluid has acceptable exergy losses in heat exchanges of high-temperature sources [38] due to it presents a low temperature difference through the heat transfer process [39]. because it allows a low temperature difference between cooled and heated fluids. The R245fa is an organic fluid in an ORC; it is often used in these cycles, in order to recover the power from heat sources at low temperatures,[7, 9, 38, 40, 41]. RC with water and ORC with R245fa will be the studied bottoming cycles to recover the waste heat in different engine working conditions for both cases (A and B). More details of this justification can be found in [21, 22], where a deep analysis of this selection was performed only for $1800 \mathrm{rpm}$ and $100 \%$ load engine operating conditions.

\subsection{Calculation with the ideal cycle assumption}

In step (5) of the proposed methodology, the performance of an ideal cycle in each engine operating point was evaluated in order to analyze which had the maximum output power through the implementation of a power cycle. The 
thermodynamics properties of the working fluid are calculated by REFPROP NIST 7.0. A parametric-iterative method has been employed to choose the optimum working fluid mass flow, vaporization and superheating temperatures for each operating point. This method was fully described by Dolz et al. [21] for the configuration with all sources at $1800 \mathrm{rpm}$ and $100 \%$ with the same case engine. The main goal of the study was to maximize the power output of the cycle while keeping the engine working conditions constant. Therefore, the increase of power output by the bottoming cycle is shown as a reduction of $b s f c$ by the IC engine. Thus, the main goal of the study was to minimize this variable.

The hypothesis assumed in this analysis was:

- Isentropic efficiencies for the expansion machine and pump processes in this ideal study are $100 \%$.

- Heat losses in the cycle are not considered.

- The waste sources were recovered from lowest to highest temperature level. The cooling water heats up the working fluid to saturated fluid. The cooling water, intercooler, aftercooler, exhaust gases and a part of the EGR heat was employed in the evaporator. The rest of EGR heated up the saturated vapor to superheated vapor. Details and thermodynamic diagrams of these processes for the $1800 \mathrm{rpm}$ and $100 \%$ load can be found in [21].

The first theoretical study (case A) deals with the implementation of a thermodynamic cycle that allows recovering all the waste heat sources of the engine. Figure 6 shows a countour lines of the reduction of $b s f c$ obtained at each engine operation point by the implementation of a RC (water cycle) and an ORC (R245fa cycle). In both configurations, a significant reduction of $b s f c$ was achieved: from $15 \%$ to $5 \%$ for RC and from $12 \%$ to $5 \%$ for the ORC. The area near $1200 \mathrm{rpm}$ is the most frequent operating zone in this HDD engine and this is also the zone with a higher improvement in $b s f c$. Some of the bottoming cycle operating conditions in case (A) configuration are listed in Table 3. At low speed (800-1000 rpm) and full load points, the EGR rate is zero. So, the exhaust gases are used to heat up the saturated vapor to superheated vapor in these points.

In the configuration with all the heat sources (case $\mathbf{A}$ ), a low temperature difference between the evaporator and condenser is imposed, in order to recover the waste heat sources that have lower temperature, i.e. $80{ }^{\circ} \mathrm{C}-95^{\circ} \mathrm{C}$ for the cooling water.

The large dissipated heat in the heat-exchangers and the complex control system are two drawbacks to implement the case $A$ configuration.

The same procedure was followed for the case $\mathbf{B}$ configuration. Figure 7 shows the results of this study. Table 3 lists the bottoming cycle conditions for two engine operative points (1800 rpm- $100 \%$ load and $1200 \mathrm{rpm}$ and $25 \%$ load.

The ORC configuration has a similar behavior as in the previous case but with a lower reduction of $b s f c$ ranging from $10 \%$ (at $1200 \mathrm{rpm}$ and $25 \%$ load) to $3 \%$ (at $800 \mathrm{rpm}$ and $100 \%$ load). This similarity is due to the optimum cycles because the superheating temperatures in ORC can not achieve a excessively high level (close to $150{ }^{\circ} \mathrm{C}$ ) as shown Table 2. But the available waste heat power was lower, because the heat power of the sources has decreased. 
The main differences were observed in the RC implementation. In this configuration with the high temperature sources, the cooling water temperature does not imply a restriction in the evaporation temperature. For this reason, higher evaporation and superheating temperatures as shown in Table 3 can be considered for the optimal cycle, for instance, at $1800 \mathrm{rpm}$ and $100 \%$ load the superheating temperatures is close to $500{ }^{\circ} \mathrm{C}$. Consequently, the reduction of $b f s c$ ranged from $10 \%$ to $14 \%$ at points of high thermal level (high speed and load), i.e. from 1200 to $1800 \mathrm{rpm}$ and $100 \%$ load. The highest reduction of $b s f c$ was achieved at $1800 \mathrm{rpm}$ and $100 \%$ load.

\subsection{Sizing heat exchangers}

The technical implementation of a bottoming cycle in a HDD engine is not only based on thermodynamic design criteria. Also, the required space, weight and cost of installation are important criteria for the viability of the considered solution. Thus, the sizing and the materials of the heat exchangers for the power cycles proposed in the theoretical study are calculated. This involves the selection of heat exchanger construction type, flow paths, physical size to meet the specified heat transfer and pressure drops within specified constraints [42]. For the sizing of the heat exchangers, the following criteria have been imposed:

- Aluminum was selected as the heat exchanger material.

- The heat exchangers were designed so that the pressure drop is less than $2 \%$, in order to be consistent with the hypotheses considered in the previous step.

- Shell\&tube heat exchangers have been chosen for the gas-liquid and liquid-liquid heat transfer. For the rating problem, the step-by-step developed by Delaware-Bell et al. [43] has been followed. An E-11 shell flow arrangement with a square pitch configuration is selected for all the shell\& tube exchangers [44]. The number of passes and the $\log$ mean temperature difference correction factor $F$ have been calculated using the Domingo's correlation [45]. The Dittus-Boelter's correlation for the heat transfer coefficient and Blasius/McAdams equations for the friction factor were used for the calculation in the tube side [46]. The ideal heat transfer coefficient for the shell side was calculated by:

$$
h_{i d}=\frac{j C_{p} G_{s}\left(\Phi_{s}\right)^{n}}{\operatorname{Pr}^{\frac{2}{3}}}
$$

where the term $j$ is the ideal Coulburn factor for the shell side and can be determined form the appropriate Bell-Delaware curve for the tube and pitch [43], $C_{p}$ is the average fluid heat capacity at constant pressure along the heat transfer process, $G_{s}$ is the shell side mass flow velocity, the term $\left(\Phi_{s}^{n}\right)$ is the viscosity correction factor, with accounts for the viscosity gradients along the tube wall versus the viscosity at the bulk mean temperature of the fluid and $\operatorname{Pr}$ is Prandtl number. The standard definition of this variable is given by Equation 5 taking into account the different temperature criteria for the gases and liquids being cooled or heated [47]: 


$$
\left(\Phi_{s}\right)^{n}=\left(\frac{\mu}{\mu_{w}}\right)^{0.14}
$$

The correction factors $J$ of the heat transfer coefficient in the shell side have been neglected. The heat transfer coefficient for the boiling process is calculated by the approach developed by Bromley et al. [48], it is used to predict the film boiling heat transfer coefficient for a horizontal tube. The heat transfer correlation used for internal condensation in horizontal tubes is proposed by Carey [49] and Ould Didi et al. [50]. The overall pressure drop due to the evaporation process was obtained by the Martinelli-Nelson's correlation [51]. The data on fouling factors were given by Ludwing [52]. The both side fouling factor was fixed to $0.0003 \mathrm{~m}^{2}{ }^{\circ} \mathrm{C} / \mathrm{W}$.

- Single-pass crossflow plate-fin exchangers have been chosen for the gas-vapor heat transfer. A similar stepby-step method for rating the single-pass crossflow plate-fin exchanger is used in order to obtain following information: Reynolds numbers, surface basis characteristics, corrections to the surface basic characteristics due to temperature-dependent properties, heat transfer coefficients and fin efficiencies, wall thermal resistance and overall thermal conductance, NTU, exchanger effectiveness, heat transfer rate and pressure drops on each fluid side [42]. The condenser is placed the behind the grille and cooled directly by the ambient. The vehicle speed is fixed at $90 \mathrm{~km} / \mathrm{h}$ due to its frequent occurrence as road truck speed, irrespective of the load and engine speed.

The operating points with greater reduction in $b s f c$ for each configuration studied were considered in order to evaluate the space requirement. Table 4 shows the selected operating points with $d T=10^{\circ} C$ (from $1 \mathbf{i}$ to $4 \mathbf{i}$ ). The dimensions and pressure drops required of the heat exchanged designed are listed in Table 4.

Figure 8 shows the heat exchanger volume obtained by using the previous criteria. The evaporator is the biggest heat exchanger in the RC and the ORC configurations of case $\mathbf{A}$ (Point $\mathbf{1 i}$ and $\mathbf{2 i}$ ), due to the large heat transfer that takes place during the evaporation process. The heating process during the liquid phase presents a low heat exchange, because the working fluid at the pump outlet is near to the saturation curve. The volume of the evaporator in case $\mathbf{A}$ is also high enough to allow such a high heat exchange rate without a high pressure drop in the shell side. The evaporator absolute pressure in the RC configuration with all the heat sources (1i) is above 0.3 bar. This implies that the heat exchanger must be designed with a large diameter and extreme length in order to avoid a high relative pressure drop as shown Table 5. This effect is less important in the ORC (2i), because the evaporator pressure is higher and the relative pressure drop is lower. The superheater size in both cases (1i and $\mathbf{2 i}$ ) is almost neglectable compared to the size of the pre-heater and evaporator.

In case $\mathbf{B}$ (Point $\mathbf{3 i}$ and $\mathbf{4 i}$ ), the largest heat exchange process is the liquid heat transfer process to the saturation curve. The heat transfer area in this process must be very high due to the higher evaporation temperature than in case A. The low temperature difference between the cold and hot flow to heat the liquid implies large areas in the heat exchange. The superheater size in $(\mathbf{3 i})$ and $(\mathbf{4 i})$ is also neglectable compared to the size of the pre-heater and evaporator. 
As shown in Figure 8, the processes of evaporation and liquid heating are the most critical heat exchange processes to the implementing of the $\mathrm{RC}$ and $\mathrm{ORC}$ configurations in a vehicle. The volume requirements for the $\mathrm{RC}$ configuration with $d T=10^{\circ} \mathrm{C}(\mathbf{1 i}$ and $\mathbf{3 i})$ could be too large for the implementation in a HDD engine. The ORC configuration seems to be the solution with less technical restrictions from the point of view of volume requirements for the heat exchangers. In steps (5) and (6) of Figure 1, an iterative process is specified; where $d T$ has to be progressively increased in order to fulfill the size due to packaging constraints in the vehicle. As we do not have any particular vehicle with a particular packaging objective, we are going to skip such iterative process and straight forward propose an increment of $d T$ from $10^{\circ} \mathrm{C}$ to $20^{\circ} \mathrm{C}$ in order to exemplify its effect on reduction of $b s f c$. The configuration with high temperature sources suffers a significant penalty of $b s f c$ in almost all the working points due to increase of $d T$. Figure 9 shows the results of this study in the configuration with high temperature sources (case B) and ideal cycle assumption. This figure shows a reduction of $b s f c$ improvements in the range of $8 \%$ to $4 \%$ for the ORC configuration, and of $11 \%$ to $2 \%$ for the RC configuration.

Respect the condenser size, the new space requirement is practically negligible due to his place in the grille and the high considered vehicle speed.

The effect of $d T=20^{\circ} \mathrm{C}$ in the sizing of the heat exchanger is evaluated for the operating points with higher reduction of $b s f c$ for the RC and ORC configuration, i.e. $1800 \mathrm{rpm}$ and $100 \%$ load for RC, and $1200 \mathrm{rpm}$ and $50 \%$ load for RC. These points are called as $\mathbf{5 i}$ and $\mathbf{6 i}$ respectively, as shown in Table 4. The results of these sizing problems are shown in Figure 10. For both configurations with high temperature sources, a $d T=20^{\circ} \mathrm{C}$ has implied a $50 \%$ reduction of the heat exchanger volume. Thus the volume requirements with $d T=20^{\circ} \mathrm{C}$ are more acceptable. According to these results, the ORC with the high temperature sources could be the solution easier to implement in a HDD engine taking installation constraints into account.

The configuration with all sources (case A) practically does not produce a net power output. It is result of the low temperature difference imposed between evaporator and condenser in order to recover the waste heat of cooling water. This temperature difference is so low that it doesn't allow increasing the minimum temperature difference in the heat exchangers $(d T)$.

The condenser size in these two configuration is also negligible compared to the other evaporator and pre-heater.

\subsection{Influences of real expander and pump}

In this section, the effects of internal irreversibilities in the cycle output power are evaluated. These irreversibilities are considered only in the expander and the pump. The pump model is simulated with a isentropic compression efficiency of $80 \%$ [6]. The isentropic expansion efficiency of the turbine is determined using the turbine chart which is referenced in [24]. In this chart, the optimal expander and the isentropic efficiency can be obtained from two dimensionless numbers: the Load Number and the Flow Number. These coefficients are calculated though the inlet and outlet conditions of the expander machine [25]. 
In the case $\mathbf{A}$ with all the heat sources and $d T=10^{\circ} \mathrm{C}$ an expansion ratio of 3 and 2 for $\mathrm{RC}$ and $\mathrm{ORC}$ respectively is produced in the expander machine at all the operating points. The reason for these low expansion ratios is the low evaporation temperature imposed, in order to recover the cooling water heat source. It allows an expansion process completed with a single expander machine, obtaining an acceptable isentropic efficiency of $70 \%$. Regarding the type of expander, the chosen solution for $\mathrm{RC}$ is a reciprocating piston expander. In the ORC case, the expander can be a radial or axial turbine.

On the other hand, in the case B with high temperature sources (EGR, exhaust gases and aftercooler), a high expansion ratio is produced in the expander as shown in Figure 11. In the ORC results, the expansion ratio is higher than in case A (6 vs 2). The optimal solution for this configuration using the turbine chart referenced in [24] is still an axial or radial turbine with an isentropic efficiency of $70 \%$. On the other hand, the expansion ratio in RC configuration ( 25 with high temperature sources vs 3 with all sources) is too large to be efficiently implemented in a single stage expansion. Thus, the optimal expander is a two-stage reciprocating piston expander with $70 \%$ and $60 \%$ of isentropic efficiency for the first and second stage respectively.

The irreversibilities of the expander machine and the pump are imposed in the studied configurations.

Figure 12 shows the effects of the real compression and expansion processes in the four studied cases with $d T=10^{\circ} \mathrm{C}$. In the configuration with all sources, the irreversibilities of the expander machine are less critical, because the low expansion ratio provides the possibility of using a single stage expander. Now, the highest reduction obtained in $b s f c$ for the case $\mathbf{A}$ is limited to $10 \%$, at $1200 \mathrm{rpm}$ and $25 \%$ load both for RC and ORC solution. An even greater impact on $b s f c$ is obtained in the case $\mathbf{B}$ configuration with a maximum reduction of $b s f c$ above $10 \%$ at 1800 rpm and $100 \%$ load and $7 \%$ at $1200 \mathrm{rpm}$ and 25\% load for RC and ORC respectively.

Figure 13 shows the effects of the expander and pump irreversibilities with $d T=20^{\circ} \mathrm{C}$ in the case $\mathbf{B}$. The highest reduction in this case is above $8 \%$ at $1800 \mathrm{rpm}$ and $100 \%$ load for $\mathrm{RC}$ and $5 \%$ at $1200 \mathrm{rpm}$ and $25 \%$ load for ORC solution.

The effect of the pump and expander irreversibilities in the heat exchanger inlet temperature is almost negligible. For this reason, the volume requirements were considered equal to those in the ideal cycle study.

\section{Summary}

Table 6 is a summary showing the highlighted numerical results of the illustrative example exposed through this paper. The table shows the performance and requirement at optimum solution for each operating point. Taking into account the ideal cycle assumption, $d T=10^{\circ} \mathrm{C}$ and the configuration with all the sources (A), the bottoming cycle reaches a maximum reduction of $b s f c$ near $15 \%$ and $14 \%$, for $\mathrm{RC}$ and $\mathrm{ORC}$ respectively (cases $\mathbf{1 i}$ and $\mathbf{2 i}$ ). The case $\mathbf{B}$, with only the high temperature heat sources, ideal cycle and $d T=10^{\circ} \mathrm{C}$ can achieve a reduction near $14 \%$ and $10 \%$ for RC and ORC respectively (cases $\mathbf{3 i}$ and $\mathbf{4 i}$ ). The RC configurations need a high heat exchanger surface and 
volume to run. The ORC configurations are therefore more technically feasible, due to the lower size requirements of the heat exchangers.

The temperature difference between the hot and the cold flow $(d T)$ dramatically affects to the reduction of $b s f c$. A change from $d T=10^{\circ} \mathrm{C}$ to $d T=20^{\circ} \mathrm{C}$ reduces the size of the heat exchangers by about $50 \%$, but this change also increases the $b s f c$ by about 3 percentage points.

Finally, the results show that the irreversibilities in the expander and pump can lead to an increase between 2 and 4 percentage points the $b s f c$. In concrete terms, 3 percentage points of $b s f c$ increment in the most feasible case (6r) with respect to the ideal $(\mathbf{6 i})$ case.

\section{Conclusions}

This paper describes a methodology to optimize a bottoming cycle which recovers low temperature waste heat sources to generate mechanical power in vehicles. The methodology followed is to select the waste heat sources, the optimum working fluid, the expander machine, the pump, the heat exchangers and the thermodynamic characteristics of the cycle, according to different initial limitations or goals initially established. The goals are usually a reduction in $b s f c$, with a low effect on the engine space requirements and low costs. In order to illustrate the methodology, the case of an implementation of a bottoming cycle in a HDD engine has been described and a realistic result of a maximum improvement of about $5 \%$ in $b s f c$ has been obtained. In the heat sources selection, a power and exergy study of each waste heat source is required in order to analyze which ones are the most useful for the generation of power output. Taking different criteria into account, depending on the problem to solve, the optimal solution can be the recovering of all the available heat sources or only the available heat sources with high temperature levels. Many heat sources to recover imply high output power in the bottoming cycle but unfortunately, it also implies high heat exchanger volumes and a complex control of the cycle and additionally, it can decrease the bottoming cycle average efficiencies.

The working fluid selection strongly affects to the performance of the bottoming cycle. Considering the case of the HDD engine, the highest reduction in $b s f c$ is produced when the water RC is used. But these RC configurations need high heat exchanger volumes to run. The ORC configurations are more technically feasible due to lower size requirements of the heat exchangers (about 50\% lower than RC configurations), but produce lower power than the RC configurations (leading to differences of 3 percentage points in $b s f c$ ).

The minimum temperature difference in the heat exchangers $(d T)$ dramatically affects the reduction of $b s f c$. So, the heat exchanger sizing must be determined correctly to optimize the $b s f c$ with low space requirement. In the case of the HDD engine, changing the $d T$ from $10{ }^{\circ} \mathrm{C}$ to $20{ }^{\circ} \mathrm{C}$ leads to a decrease of the volume required by the heat exchangers by about $60 \%$ and increases the $b s f c$ by about 3 percentage points.

Therefore, considering the complexity of selecting the heat sources, the working fluid and the minimum temperature difference in the heat exchangers, this paper presents an iterative methodology to obtain the goal defined in the 
design of a bottoming Rankine cycle for a vehicle; with ground rules about the potential impact of the main design assumption.

Finally, a literature review has been done to select the expander and the pump and analyze the effect of their irreversibilitites. Considering the case of a HDD engine, the expander obtained is a reciprocating piston expander for $\mathrm{RC}$ and a radial turbine or axial turbine for ORC. The results show that these irreversibilities can involve an increase between 2 and 4 percentage points in the calculated $b s f c$.

Therefore, considering the complexity of selecting the heat sources, the working fluid and the minimum temperature difference in the heat exchangers, this paper presents an iterative methodology to obtain the goal defined in the design of a bottoming Rankine cycle for a vehicle; with ground rules about the potential impact of the main design assumption.

\section{Acknowledgements}

This work was partially funded by the "Programa de Formación de Profesorado Universitario (FPU)", "Programa de Apoyo a la Investigación y Desarrollo de la Universidad Politécnica de Valencia 2010", "Proyectos I+D para grupos de investigación emergentes 2011" and "Programa de apoyo a la investigación y desarrollo de la U.P.V (PAID-06-09)". The authors thank J. Dahlqvist for his help in improving the English grammar. 


\section{References}

[1] Pavlas M, Tous M, Bébar L, Stehlík P. Waste to energy- An evaluation of the environmental impact. Applied Thermal Engineering 2010; 20;2326-32.

[2] Ammar Y, Joyce S,Norman R, Wang Y, Roskilly AP .Low grade thermal energy sources and uses from the process industry in the UK. Applied Energy 2012;89;3-20.

[3] Key World Energy Statistics. International Energy Agency 2008.

[4] Marrero GA. Greenhouse gases emissions, growth and the energy mix in Europe. Energy Economics 2010;32;135663.

[5] Keeling CD, Whorf TP. Atmospheric CO2 records from sites in the SIO air sampling network. In Trends: A compendium of data on global change. Technical Report, Oak Ridge National Laboratory, U.S. Department of Energy, Oak Ridge, Tenn,U.S.A., 2005.

[6] Chacartegui R, Sánchez D, Muoz JM, Sánchez T. Alternative ORC bottoming cycles FOR combined cycle power plant. Applied Energy 2009;86:2162-70.

[7] Wang J, Dai Y, Gao L. Exergy analyses and parametric optimizations for different cogeneration power plants in cement industry. Applied Energy 2009;86:941-8.

[8] Bianchi M, Pascale AD. Bottoming cycles for electric energy generation: Parametric investigation of available and innovative solutions for the exploitation of low and medium temperature heat sources, Applied Energy 2011;88;1500-9.

[9] Wei D, Lu X, Lu Z and. Gu J. Performance analysis and optimization of organic Rankine cycle (ORC) for waste heat recovery. Energy Conversion and Management 2007;48:1113-9.

[10] Cayer E, Galanis A, Nesreddine H. Parametric study and optimization of a transcritical power cycle using a low temperature source. Applied Energy 2010;87;1349-1357.

[11] Shengjun Z, Huaixin W, Tao G .Performance comparison and parametric optimization of subcritical Organic Rankine Cycle (ORC) and transcritical power cycle system for low-temperature geothermal power generation. Applied Energy 2011;88;2740-2754.

[12] Roy JP, Mishra MK, Misra A. Performance analysis of an Organic Rankine Cycle with superheating under different heat source temperature conditions. Applied Energy 2011;88;2995-3004.

[13] Algieri A, Morrone P.Comparative energetic analysis of high-temperature subcritical and transcritical Organic Rankine Cycle (ORC). A biomass application in the Sibari district. Applied Thermal Engineering 2012 36;236-44.

[14] Garcia RF.Efficiency enhancement of combined cycles by suitable working fluids and operating conditions. Applied Thermal Engineering 2012, doi: 10.1016/j.applthermaleng.2012.02.039.

[15] Wang EH, Zhang HG, Fan BY, Ouyang MG, Mu QH. Study of working fluid selection of organic Rankine cycle (ORC) for engine waste heat recovery. Energy 2012 36;3406-18.

[16] Eurostat, Statistical Office of the European Communities: Energy, transport and environment indicators. On the web:http://www.epp.eurostat.ec.europa.eu.

[17] Morsy El Gohary M, Abdou KM. Computer based selection and performance analysis of marine diesel engine. Alejandria Engineering Journal 2011;50;1-11.

[18] Arias DA, Shedd TA, Jester RK. Theoretical analysis of waste heat recovery from an internal combustion engine in a hybrid vehicle. SAE Paper 2006;2006-01-1605.

[19] Teng H, Regner G. Improving fuel economy for HD Diesel Engines with EHR Rankine cycle driven by EGR cooler heat rejection. SAE Paper 2009;2009-01-2913.

[20] Ringler J, Seifert M, Guyotot V, Hübner W. Rankine cycle for waste heat recovery of IC engines. SAE Paper 2009;2009-01-0174.

[21] Dolz V, Novella R.,García A, Sánchez J. HD Diesel engine equipped with a bottoming Rankine cycle as waste heat recovery system. Part 1: Study and analysis of the waste heat energy. Applied Thermal Engineering 2011;36:269-78.

[22] Serrano JR, Dolz V, Novella R, García A. HD Diesel engine equipped with a bottoming Rankine cycle as waste heat recovery system. Part 2: Evaluation of alternative solutions. Applied Thermal Engineering 2011;36:279-87 
[23] Emission Standards for Model Year 2007 and Later Heavy-duty Highway Engines. U.S Environmental Protection Agency (EPA) (http://www.epa.gov/).

[24] NSDS Turbine Chart Map.[cited 2012 Jan 20]. On the Web: www.barber-nichols.com/pdf/nsds_turbine_chart.pdf.

[25] Japikse D, Baines NC, (1997): Introduction to Turbomachinery. ETI, Inc. and Oxford, Oxford.

[26] Saleh B. Working fluids for low-temperature organic Rankine cycles. Energy 2007;32;1210-21.

[27] Angelino G, di Paliano PC. Organic Rankine Cycles (ORCs) for energy recovery from molten carbonate fuel cells. Intersociety Energy Conversion Engineering 2000;2:1400-9.

[28] Drescher U. and Brüggemann D. Fluid selection for the Organic Rankine Cycle (ORC) in biomass power and heat plants. Applied Thermal Engineering 2007;27:223-8.

[29] Serrano JR, Arnau FJ, Dolz V, Tiseira A, Lejeune M, Auffret N. Analysis of the capabilities of a two-stage turbocharging system to fulfil the US2007 anti-pollution directive for heavy duty Diesel engines. International Journal of Automotive Technology 2008;9:277-88.

[30] Armstrong M. Basic Linear Geostatistics. Springer, Berlin ;1998.

[31] Surfer Version 8.0. Feb 112002.

[32] Energy and Exergy Balances for Modern Diesel and Gasoline Engines, Les recontrates scientifiques de 1 IFP- Advances in Hybrid Powertrains, 2008.

[33] Exergy analysis- a different perspective on energy- Part 2: rational efficiency and some examples of exergy analysis. SAE Technical Paper 904794,1990

[34] Bourhis G, Leduc P, IFP. Energy and Exergy Balances for Modern Diesel and Gasoline Engines, Les recontrates scientifiques de 1 IFPAdvances in Hybrid Powertrains, 2008.

[35] Tchanche BF, Lambrinos G, Frangoudakis A, Papadakis G. Exergy analysis of micro-organic Rankine power cycles for a small scale solar driven reverse osmosis desalination system. Applied Energy 2010;87;1295-306.

[36] Badr O, Probert SD, O'Callaghan PW. Selecting a working fluid for a Rankine cycle engine. Applied Energy 1985;21:1-42.

[37] Yamamoto T, Furuhata T, Ara N, More K. Design and testing of the Organic Rankine Cycle. Energy 2001;26;239-51.

[38] Duparchy A, Leduc P, Bourhis G, Ternel C. Heat Recovery for next Generation of Hybrid Vehicles: Simulations and Design of a Rankine Cycle System. World Electric Vehicle Journal Vol 3. ISSN 2023-6653, 2009.

[39] Schuster A, Karellas S, Aumann R. Efficiency optimization potential in supercritical Organic Rankine Cycles. Energy 2010;35;1033-9.

[40] Nelson C. Exhaust Recovery Energy. In: 2008 DEER Conference, August 3rd, 2008

[41] Schuster A, Karellas S, Kakaras E, Spliethoff H. Energetic and economic investigation of Organic Rankine Cycle applications. Applied Thermal Engineering 2009;29:1809-17.

[42] Shah RK, Sekulić DP. Heat Exchanger Design Procedures, in Fundamentals of Heat Exchanger Design. John Wiley and Sons, Inc, New Yersey ;2003.

[43] Bell KJ. Delaware method for shell design, in: RK Shah, EC Subbarao, RA Mashelkar, editors. Heat Transfer Equipment Design, Washintong: Hemisphere Publishing, p.145-66.

[44] Standards of the Tubular Heat Exchanger Manufactures Association, 8th edg (Tubular Heat Exchangers Manufactures Association New York).

[45] Domingo JD. Analysis of complex assemblies of heat exchangers. Int. J Heat Mass Transfer 1969;12:537-48.

[46] Bhatti MS and. Shah RK. Turbulent and transition convective heat transfer in duct. Handbook of Single-Phase convective Heat transfer, New York:Wiley; 1987.

[47] Taborek J. Ideal tube bank correlations for heat transfer and pressure drop, in: EU Schlunder, editors. Heat Exchanger Design Handbook, Washintong: Hemisphere Publishing; 1983.

[48] Bromley LA. Heat transfer in stable film boiling. Chemical Engineering Programe 1950;46:221-7.

[49] Carey VP. Liquid-Vapor Phase-Change Phenomena: An Introduction to the Thermophysics of Vaporization and Condensation Process in Heat Transfer Equipment, Taylor \& Francis, Bristol; 1992. 
[50] Ould Didi MB, Kattan N, Thome JR. Prediction of two-phase pressure gradients of refrigerants in horizontal tubes. Int. J. Refrigeration 2002; 25:716-30.

494 [51] Martinelli RC, Nelson B. Prediction of Pressure Drop during Forced-circulation Boiling Water. Transaction of ASME 1948; 70, 695-702.

495 [52] Ludwig EE. Applied Process Design for Chemical and Petroleum Plants, 3rd ed: Gulf Professional Publishing;2001.

496 [53] Kern DQ, Process Heat Transfer, New York: McGraw-Hill Book Co.;1950.

[54] Shah RK, Plate fin and tube-fin heat exchangers design procedures, in: Shah RK, Subbarao EC, Mashelkar RA editors. Heat Transfer Equipment Design, Washintong: Hemisphere Publishing, p 225-66. 
Nomenclature Acronyms

$B C$

$b s f c$

CFC

EGR

HCFC

$H F C$

$H D D$

HFC

HP

IC

$L P$

$O C D E$

ORC

$R C$

$S C$

499

\section{NOTATION}

Latin

$C_{p}$

$C^{*}$

$D$

$d T$

E

Ex

F

G

$h$

j

$J$

L

Lx

Ly
Bryton Cycle

Brake specific fuel consumption

Chrorofluorocarbon

Exhaust Gases Recirculation

Hydrochlorofluorocarbons

Hydrofluorocarbons

Heavy Duty Diesel

Hydrofluorocarbons

High Pressure

Internal Combustion

Low Pressure

Organization for Economic Co-operation and Development

Organic Rankine Cycle

Rankine Cycle

Stirling Cycle

Heat capacity at constant pressure $(\mathrm{kJ} / \mathrm{kg} . \mathrm{K})$

Heat capacity rate ratio

Heat exchanger diameter $(\mathrm{m})$

Minimum temperature difference in the heat exchanger $\left({ }^{\circ} \mathrm{C}\right)$

Energy (kW)

Exergy (kW)

Log mean temperature difference correction factor

Mass flow velocity

Specific enthalpy $(\mathrm{kJ} / \mathrm{kg})$

Ideal Coulburn heat transfer factor for the shell side

Correction factors of the heat transfer coefficient in the shell-side

Heat exchanger length (m)

Heat exchanger length in $\mathrm{x}$ direction $(\mathrm{m})$

Heat exchanger Length in y direction (m) 


$\begin{array}{ll}L z & \text { Heat exchanger length in z direction }(\mathrm{m}) \\ m & \text { Mass flow }(\mathrm{kg} / \mathrm{s}) \\ N T U & \text { Number of transfer unit } \\ P r & \text { Prandtl number } \\ T & \text { Temperature }\left({ }^{\circ} \mathrm{C}\right) \\ r p m & \text { Revolution per minute } \\ s & \text { Specific Entropy }(\mathrm{kJ} / \mathrm{kg} \cdot \mathrm{K})\end{array}$

500

Greek letters

$\begin{array}{ll}\Delta & \text { Increment } \\ \mu & \text { Viscosity }\end{array}$

Subscripts

flow

Waste sources mass flow

$s$

Shell side

w Wall conditions

0 Environmental condition

1 Inlet condition

2 Outlet condition 
- Table 1. Operating points chosen for design bottoming cycle.

- Table 2. Energetic and exergetic levels for the waste heat sources at $1800 \mathrm{rpm}-100 \%$ load and $1200 \mathrm{rpm}$ $25 \%$ load.

- Table 3. Optimal bottoming cycle conditions at $1800 \mathrm{rpm}-100 \%$ load and $1250 \mathrm{rpm}-25 \%$ load considering ideal cycle assumption for both configurations (Case $\mathbf{A}$ and Case $\mathbf{B}$ )

- Table 4. Bottoming cycle point chosen for the sizing of heat exchanger study.

- Table 5. Specification heat exchanger of points from 1i to $4 \mathbf{i}$.

- Table 6. Summary of the optimum engine operating point for the considered configurations

- listed of Figures

- Figure 1. Flow chart for detailed methodology of preliminary design of a bottoming cycle for recovering waste heat power in vehicles.

- Figure 2. HDD engine scheme.

- Figure 3. Total Waste Power in the HDD Engine (Stripped circles represent operating points experimentally measured) .

- Figure 4. Total Waste Exergy in the HDD Engine (Stripped circles represent operating points experimentally measured) .

- Figure 5. Exergy contribution of EGR, exhaust gases and aftercooler as a ratio of the total wasted exergy .

- Figure 6. Reduction rate of $b s f c$ with an $\mathrm{ORC} / \mathrm{RC}$ for the configuration with all the sources configuration (case $\mathbf{A})$.

- Figure 7. Reduction rate of $b s f c$ with an ORC/RC for the configuration with high temperature sources (case B).

- Figure 8. Volume requirements for the implementation of a bottoming cycle in four optimum operating points selected in Table 2 .

- Figure 9. Reduction rate of $b s f c$ in the configuration with high temperature sources (case $\mathbf{B}, d T=20^{\circ} \mathrm{C}$ ideal cycle assumption).

- Figure 10. Volume requirements for the implementation of a bottoming cyle in two optimum operating points selected in Table 2 .

- Figure 11. Expansion ratio in the expander machine for the configuration with high temperature sources (case B) and $d T=10^{\circ} \mathrm{C}$ 
- Figure 12. Reduction rate of $b s f c$ with real expander and pump with $d T=10^{\circ} C$ for case $\mathbf{A}$ (Top) and case B (Bottom)

- Figure 13. Reduction rate of $b s f c$ with real expander and pump with $d T=20^{\circ} C$ for case $\mathbf{B}$. 


Table 1: Operating points chosen for design bott
\begin{tabular}{cc}
\hline Speed (rpm) & Load (\%) \\
\hline 600 & 0 \\
\hline 800 & 100 \\
\hline 1000 & 100 \\
\hline & 25 \\
1200 & 50 \\
& 75 \\
& 100 \\
\hline 1500 & 50 \\
& 100 \\
\hline 1800 & 50 \\
& 100 \\
\hline
\end{tabular}


Table 2: Energetic level for the waste heat sources at $1800 \mathrm{rpm}-100 \%$ load and $1200 \mathrm{rpm}-25 \%$ load

\begin{tabular}{|c|c|c|c|c|c|c|c|c|}
\hline $\begin{array}{l}\text { Speed } \\
(\mathrm{rpm})\end{array}$ & $\begin{array}{c}\text { Load } \\
(\%)\end{array}$ & Variable & $\begin{array}{l}\text { EGR } \\
(\mathrm{kW})\end{array}$ & $\begin{array}{c}\text { Exhaust gases } \\
(\mathrm{kW})\end{array}$ & $\begin{array}{l}\text { Aftercooler } \\
\qquad(\mathrm{kW})\end{array}$ & $\begin{array}{c}\text { Intercooler } \\
(\mathrm{kW})\end{array}$ & $\begin{array}{l}\text { Cooling water } \\
\qquad(\mathrm{kW})\end{array}$ & $\begin{array}{l}\text { Total } \\
(\mathrm{kW})\end{array}$ \\
\hline \multirow[t]{2}{*}{1800} & 100 & Power & 75 & 147 & 21 & 30 & 151 & 424 \\
\hline & & Exergy & 40 & 60 & 5 & 4 & 26 & 135 \\
\hline \multirow[t]{2}{*}{1200} & 25 & Power & 16 & 53 & 10 & 4 & 51 & 134 \\
\hline & & Exergy & 6 & 20 & 1 & 0 & 8 & 35 \\
\hline
\end{tabular}


Table 3: Optimal bottoming cycle conditions at $1800 \mathrm{rpm}-100 \%$ load and $1250 \mathrm{rpm}$ and $25 \%$ load considering ideal cycle assumption for both configurations (Case $\mathbf{A}$ and Case $\mathbf{B}$ )

\begin{tabular}{|c|c|c|c|c|c|c|c|}
\hline Case & $\mathrm{rpm}$ & $\begin{array}{c}\text { Load } \\
(\%)\end{array}$ & Cycle & $\begin{array}{c}\text { Mass Flow } \\
(\mathrm{kg} / \mathrm{s})\end{array}$ & $\begin{array}{c}\text { Condensation } \\
\text { Temperature } \\
(\circ C)\end{array}$ & $\begin{array}{c}\text { Evaporation } \\
\text { Temperature } \\
(\circ C)\end{array}$ & $\begin{array}{c}\text { Superheating } \\
\text { Temperature } \\
(\circ C)\end{array}$ \\
\hline \multirow{4}{*}{ A } & 1800 & 100 & ORC & 2.40 & 50 & 71 & 80 \\
\hline & & & $\mathrm{RC}$ & 0.20 & 50 & 70 & 177 \\
\hline & 1200 & 25 & ORC & 1.37 & 50 & 71 & 71 \\
\hline & & & $\mathrm{RC}$ & 0.10 & 50 & 70 & 159 \\
\hline \multirow{4}{*}{ B } & 1800 & 100 & ORC & 0.54 & 50 & 130 & 150 \\
\hline & & & $\mathrm{RC}$ & 0.06 & 50 & 130 & 480 \\
\hline & 1200 & 25 & ORC & 0.17 & 50 & 130 & 150 \\
\hline & & & $\mathrm{RC}$ & 0.01 & 50 & 130 & 350 \\
\hline
\end{tabular}


Table 4: Bottoming cycle point chosen for the sizing of heat exchanger study

\begin{tabular}{ccccccc}
\hline \hline $\begin{array}{c}\text { Case } \\
\text { Problem }\end{array}$ & $\begin{array}{c}\text { Working } \\
\text { fluid }\end{array}$ & rpm & $\begin{array}{c}\text { Load } \\
(\%)\end{array}$ & Cycle & $\begin{array}{c}d T \\
(\circ C)\end{array}$ & $\begin{array}{c}\text { Nomenclature of } \\
\text { operating point }\end{array}$ \\
\hline A & Water(RC) & 1200 & 25 & Ideal & 10 & $\mathbf{1 i}$ \\
A & R245fa(ORC) & 1200 & 25 & Ideal & 10 & $\mathbf{2 i}$ \\
B & Water(RC) & 1800 & 100 & Ideal & 10 & $\mathbf{3 i}$ \\
B & R245fa(ORC) & 1200 & 25 & Ideal & 10 & $\mathbf{4 i}$ \\
B & R245fa(ORC) & 1200 & 25 & Ideal & 20 & $\mathbf{5 i}$ \\
B & R245fa(ORC) & 1200 & 25 & Ideal & 20 & $\mathbf{6 i}$ \\
\hline \hline
\end{tabular}


Table 5: Specification heat exchanger of points from $\mathbf{1 i}$ to $\mathbf{4 i}$

\begin{tabular}{|c|c|c|c|c|c|}
\hline $\begin{array}{c}\text { Operating } \\
\text { point }\end{array}$ & $\begin{array}{c}\text { Heat } \\
\text { Exchanger }\end{array}$ & $\begin{array}{l}\text { Waste } \\
\text { Source }\end{array}$ & $\begin{array}{l}\text { Geometric } \\
\text { specification }\end{array}$ & $\begin{array}{l}\text { Pressure drop } \\
\qquad(\mathrm{Pa})\end{array}$ & $\begin{array}{l}\text { Volume } \\
\qquad\left(\mathrm{m}^{3}\right)\end{array}$ \\
\hline \multirow{5}{*}{$\mathbf{1 i}$} & Pre-heater & Cooling water & $\mathrm{L}=0.4 \mathrm{~m} ; \mathrm{D}=0.7 \mathrm{~m}$ & 35 & 0.049 \\
\hline & Evaporator & Aftercooler & $\mathrm{L}=6 \mathrm{~m} ; \mathrm{D}=0.48 \mathrm{~m}$ & 125 & 0.346 \\
\hline & & Exhaust gases & $\mathrm{L}=9.6 \mathrm{~m} ; \mathrm{D}=0.6 \mathrm{~m}$ & 210 & 0.864 \\
\hline & & EGR & $\mathrm{L}=0.6 \mathrm{~m} ; \mathrm{D}=0.3 \mathrm{~m}$ & 50 & 0.4239 \\
\hline & Superheater & EGR & $\mathrm{Lx}=0.1 \mathrm{~m} ; \mathrm{Ly}=0.05 \mathrm{~m} ; \mathrm{Lz}=0.05 \mathrm{~m}$ & 279 & 0.005 \\
\hline \multirow{5}{*}{$2 \mathbf{i}$} & Pre-heater & Cooling Water & $\mathrm{L}=0.3 \mathrm{~m} ; \mathrm{D}=0.6 \mathrm{~m}$ & 2634 & 0.027 \\
\hline & Evaporator & Aftercooler & $\mathrm{L}=2.8 \mathrm{~m} ; \mathrm{D}=0.46 \mathrm{~m}$ & 949 & 0.148 \\
\hline & & Exhaust gases & $\mathrm{L}=2.64 \mathrm{~m} ; \mathrm{D}=0.39 \mathrm{~m}$ & 11000 & 0.100 \\
\hline & & EGR & $\mathrm{L}=2.64 \mathrm{~m} ; \mathrm{D}=0.2 \mathrm{~m}$ & 3518 & 0.200 \\
\hline & Superheater & - & No Superheating & - & - \\
\hline \multirow{6}{*}{$3 \mathbf{i}$} & Pre-heater & Intercooler & $\mathrm{L}=3.6 \mathrm{~m} ; \mathrm{D}=0.61 \mathrm{~m}$ & 835 & 0.335 \\
\hline & & Exhaust gases & $\mathrm{L}=5.4 \mathrm{~m} ; \mathrm{D}=0.83 \mathrm{~m}$ & 1001 & 0.93 \\
\hline & Evaporator & Aftercooler & $\mathrm{L}=1.8 \mathrm{~m} ; \mathrm{D}=0.27 \mathrm{~m}$ & 107 & 0.0320 \\
\hline & & Exhaust gases & $\mathrm{L}=3.6 \mathrm{~m} ; \mathrm{D}=0.381 \mathrm{~m}$ & 699 & 0.1300 \\
\hline & & EGR & $\mathrm{L}=1.2 \mathrm{~m} ; \mathrm{D}=0.27 \mathrm{~m}$ & 313 & 0.01714 \\
\hline & Superheater & EGR & $\mathrm{Lx}=0.07 \mathrm{~m} ; \mathrm{Ly}=0.05 \mathrm{~m} ; \mathrm{Lz}=0.07 \mathrm{~m}$ & 107 & 0.0003 \\
\hline \multirow{6}{*}{$4 i$} & Pre-heater & Intercooler & $\mathrm{L}=1.26 \mathrm{~m} ; \mathrm{D}=0.61 \mathrm{~m}$ & 1600 & 0.1172 \\
\hline & & Exhaust gases & $\mathrm{L}=2.3 \mathrm{~m} ; \mathrm{D}=0.23 \mathrm{~m}$ & 125 & 0.0304 \\
\hline & Evaporator & Aftercooler & $\mathrm{L}=1.8 \mathrm{~m} ; \mathrm{D}=0.27 \mathrm{~m}$ & 107 & 0.0320 \\
\hline & & Exhaust gases & $\mathrm{L}=3 \mathrm{~m} ; \mathrm{D}=0.34 \mathrm{~m}$ & 699 & 0.1300 \\
\hline & & EGR & $\mathrm{L}=2.3 \mathrm{~m} ; \mathrm{D}=0.25 \mathrm{~m}$ & 313 & 0.0171 \\
\hline & Superheater & EGR & $\mathrm{Lx}=0.1 \mathrm{~m} ; \mathrm{Ly}=0.05 \mathrm{~m} ; \mathrm{Lz}=0.01 \mathrm{~m}$ & 307 & 0.0030 \\
\hline
\end{tabular}


Table 6: Summary of the optimum engine operating point for the considered configurations

\begin{tabular}{|c|c|c|c|c|c|c|c|c|}
\hline $\begin{array}{c}\text { CASE } \\
\text { PROBLEM }\end{array}$ & $\begin{array}{c}\text { Working } \\
\text { Fluid }\end{array}$ & rpm & $\begin{array}{c}\text { Load } \\
(\%)\end{array}$ & $\begin{array}{l}\mathbf{d T} \\
{ }^{\circ} \mathrm{C}\end{array}$ & $\begin{array}{c}\text { Volume } \\
\text { Requeriment }\left(\mathrm{m}^{3}\right)\end{array}$ & $\begin{array}{l}\text { Expander } \\
\text { and pump }\end{array}$ & $\begin{array}{c}\% \text { reduction } \\
\quad \text { of } \boldsymbol{b} \boldsymbol{s} \boldsymbol{c} \boldsymbol{c}\end{array}$ & $\begin{array}{l}\text { Nomenclature } \\
\text { operating point }\end{array}$ \\
\hline \multirow{4}{*}{$\begin{array}{c}\text { A } \\
\text { (All Sources) }\end{array}$} & \multirow[t]{2}{*}{ Water (RC) } & \multirow[t]{2}{*}{1200} & \multirow[t]{2}{*}{25} & \multirow[t]{2}{*}{10} & \multirow[t]{2}{*}{1.68} & Ideal & 15 & $1 \mathbf{i}$ \\
\hline & & & & & & Real & 10 & 1r \\
\hline & \multirow[t]{2}{*}{ R245fa (ORC) } & \multirow[t]{2}{*}{1200} & \multirow[t]{2}{*}{25} & \multirow[t]{2}{*}{10} & \multirow[t]{2}{*}{0.48} & Ideal & 14 & $2 \mathbf{i}$ \\
\hline & & & & & & Real & 10 & $2 \mathbf{r}$ \\
\hline \multirow{8}{*}{$\begin{array}{c}\text { B } \\
\text { (High Sources) }\end{array}$} & \multirow[t]{4}{*}{ Water (RC) } & \multirow[t]{4}{*}{1800} & \multirow[t]{4}{*}{100} & \multirow[t]{2}{*}{10} & \multirow[t]{2}{*}{1} & Ideal & 14 & $3 \mathbf{i}$ \\
\hline & & & & & & Real & 10 & $3 \mathbf{r}$ \\
\hline & & & & \multirow[t]{2}{*}{20} & \multirow[t]{2}{*}{0.65} & Ideal & 10 & $5 i$ \\
\hline & & & & & & Real & 8 & $5 r$ \\
\hline & \multirow[t]{4}{*}{ R245fa (ORC) } & \multirow[t]{4}{*}{1200} & \multirow[t]{4}{*}{25} & \multirow[t]{2}{*}{10} & \multirow[t]{2}{*}{0.27} & Ideal & 10 & $4 i$ \\
\hline & & & & & & Real & 7 & $4 r$ \\
\hline & & & & \multirow[t]{2}{*}{20} & \multirow[t]{2}{*}{0.17} & Ideal & 8 & $6 \mathbf{i}$ \\
\hline & & & & & & Real & 5 & $6 r$ \\
\hline
\end{tabular}




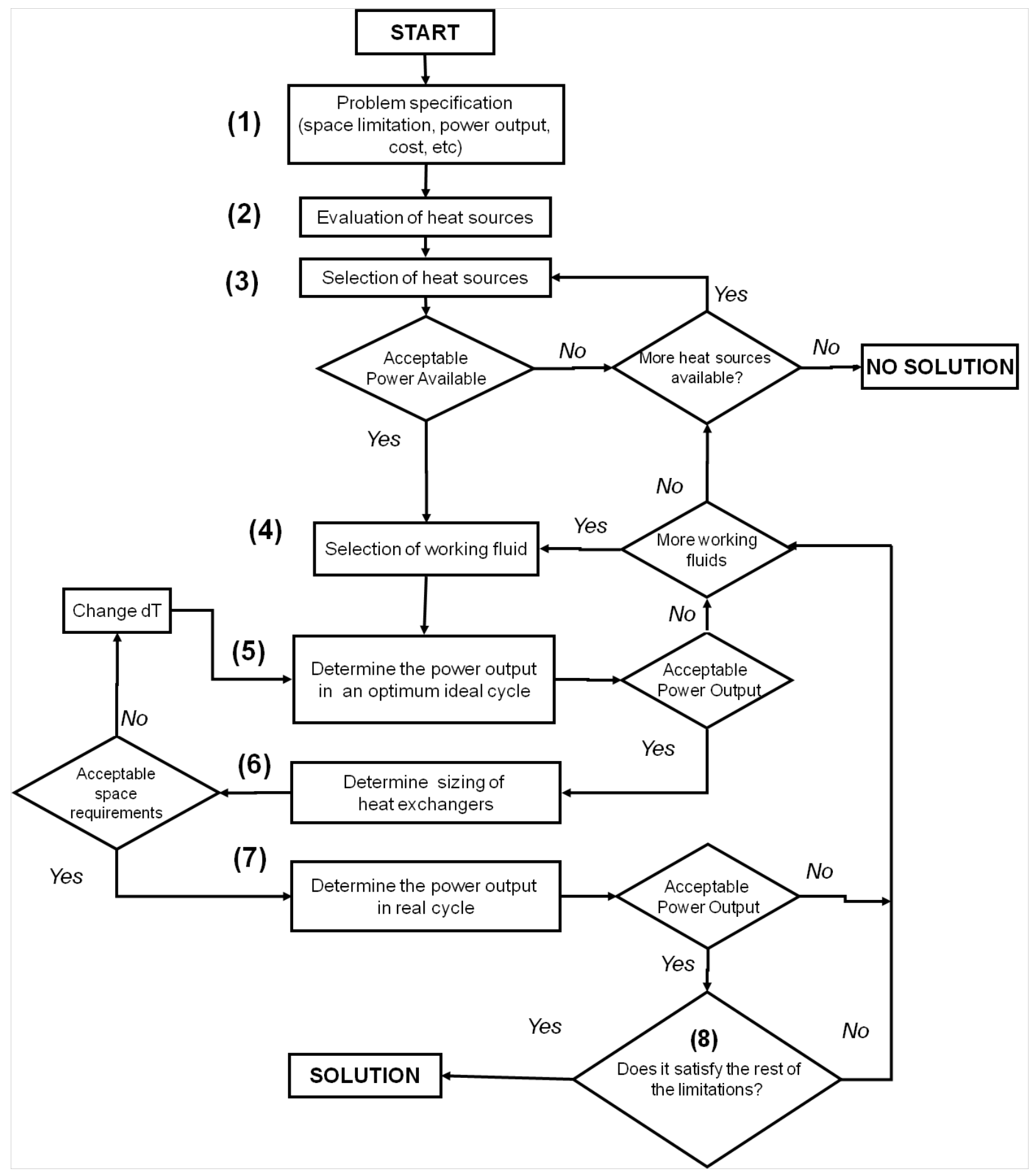

Figure 1: Flow chart for detailed methodology of preliminary design of a bottoming cycle for recovering waste heat power in vehicles 


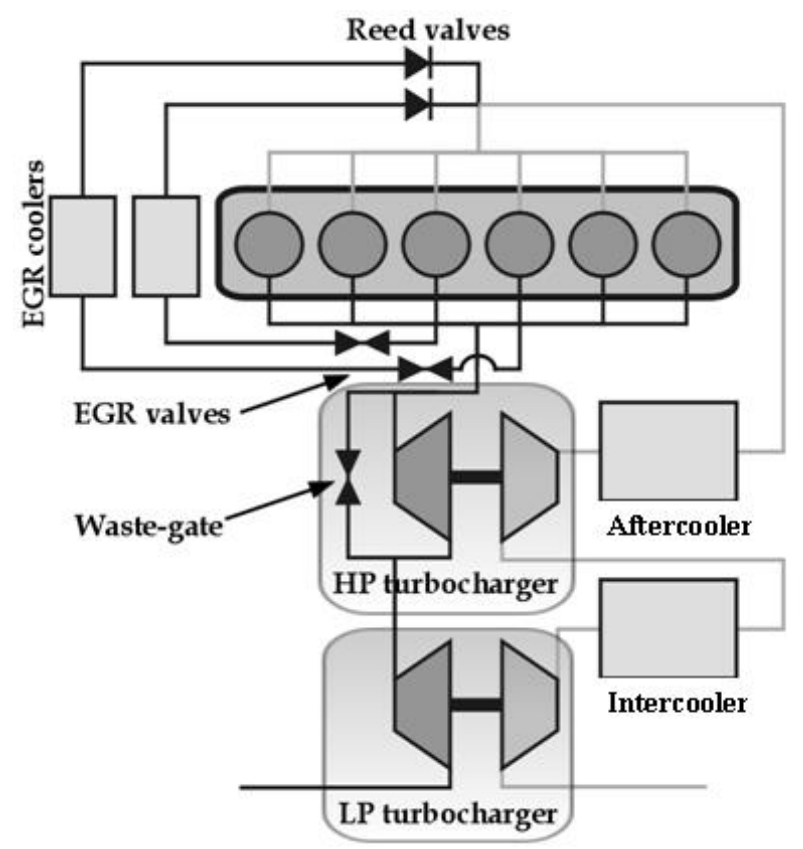

Figure 2: HDD engine scheme 


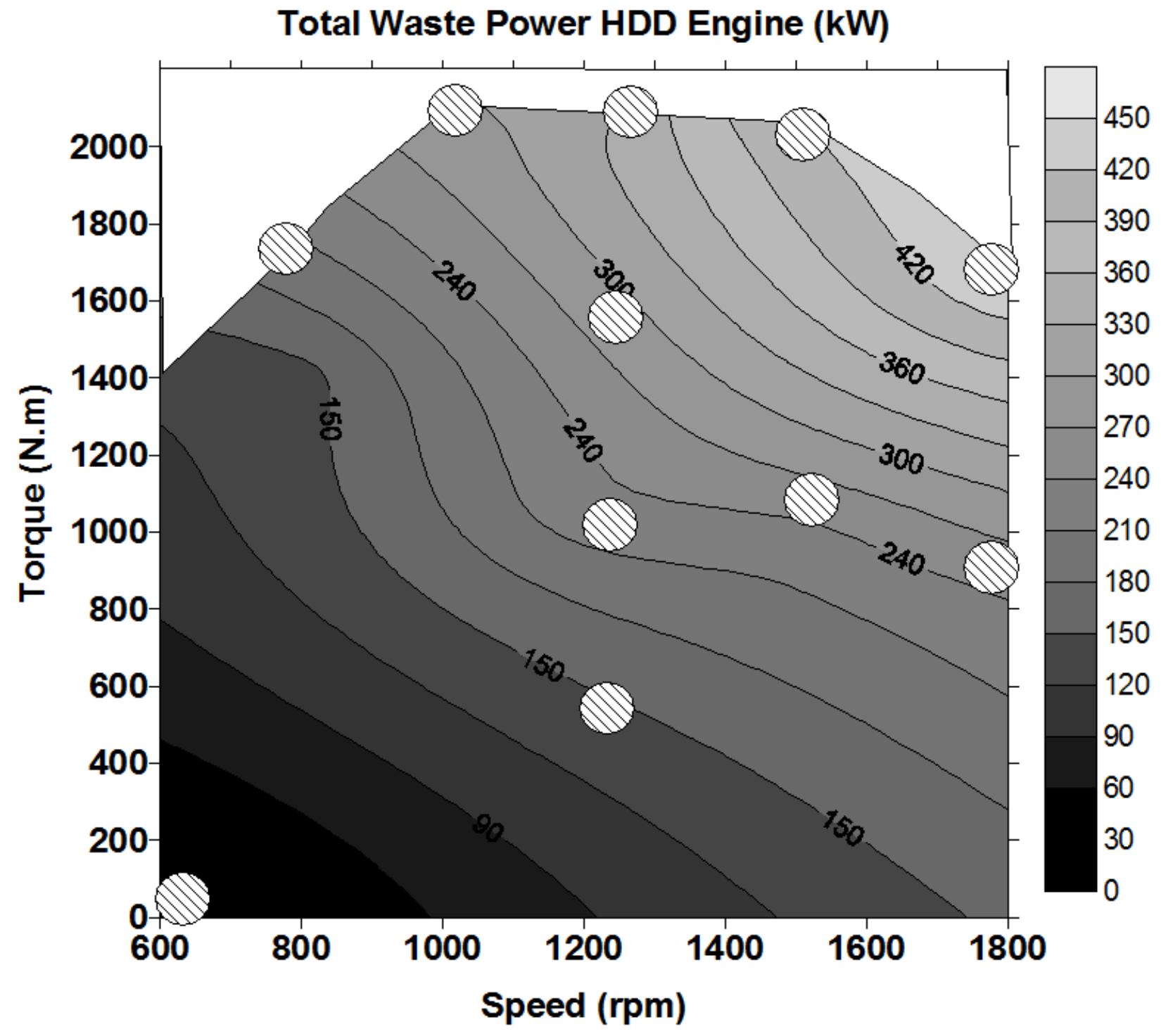

Figure 3: Total Waste Power in the HDD Engine (Stripped circles represent operating points experimentally measured) 


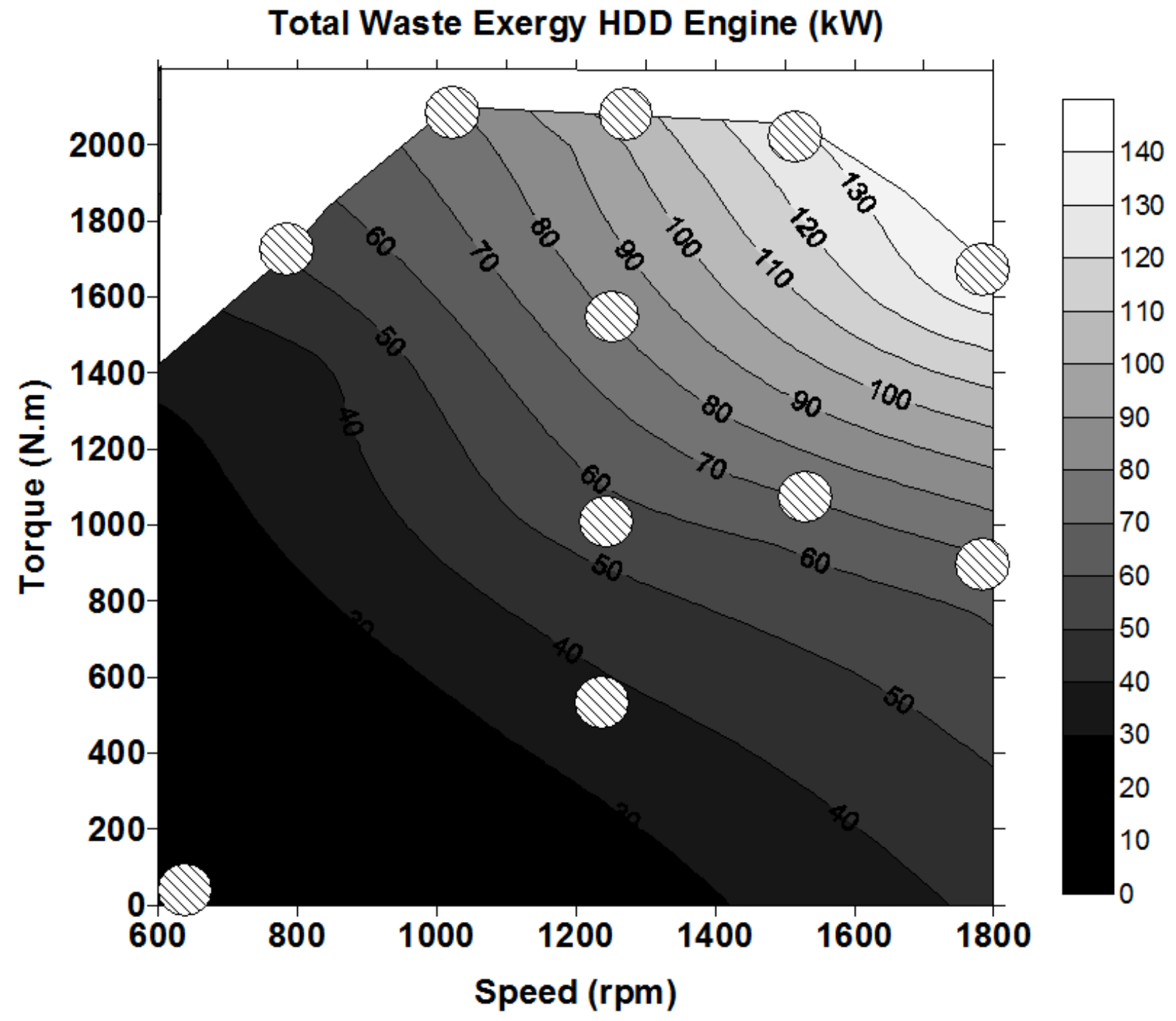

Figure 4: Total Waste Exergy in the HDD Engine (Stripped circles represent operating points experimentally measured) 

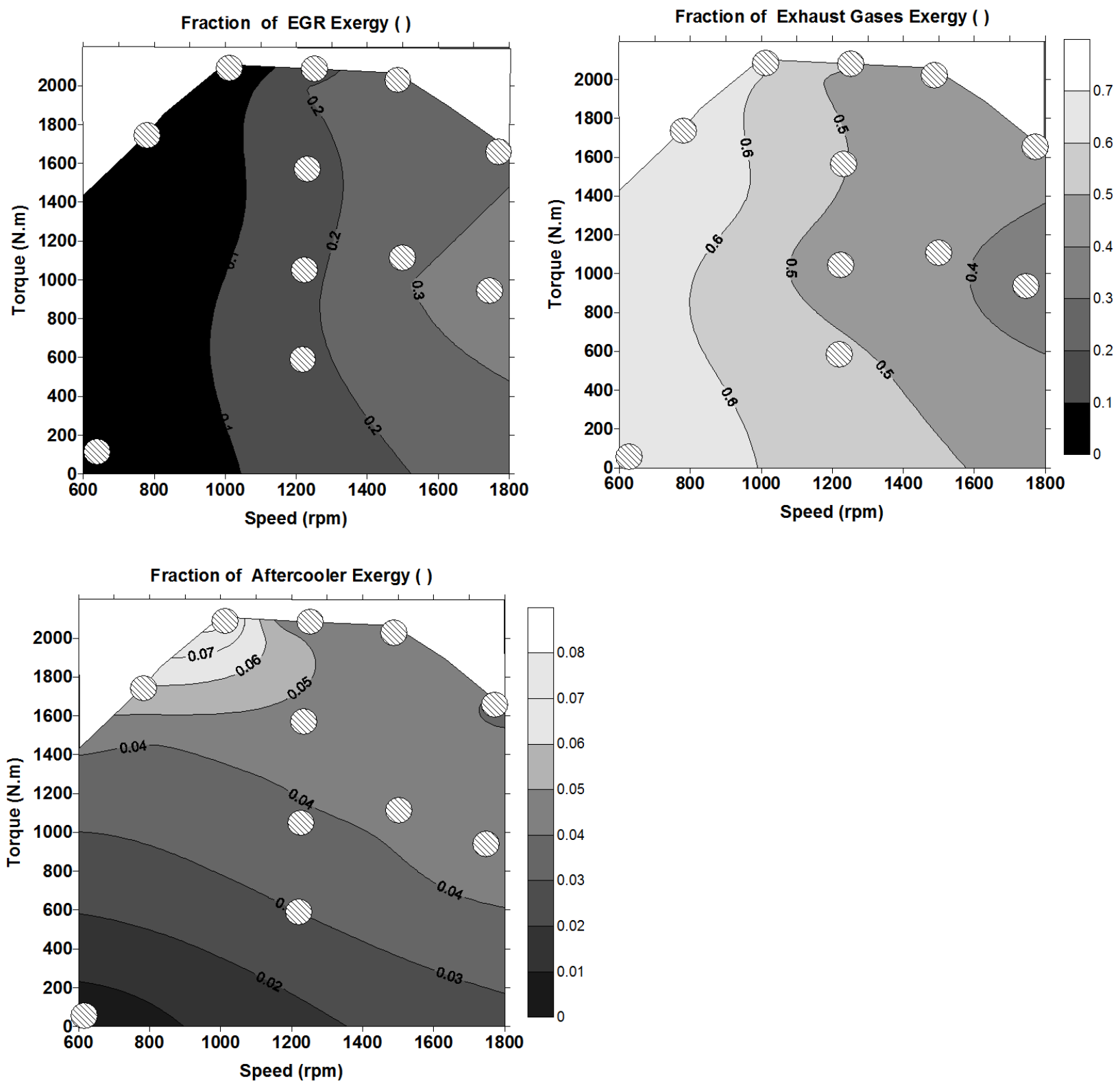

Figure 5: Exergy contribution of EGR, exhaust gases and aftercooler as a ratio of the total wasted exergy 
Reduction rate of bsfc ORC ( Configuration with all the waste sources)

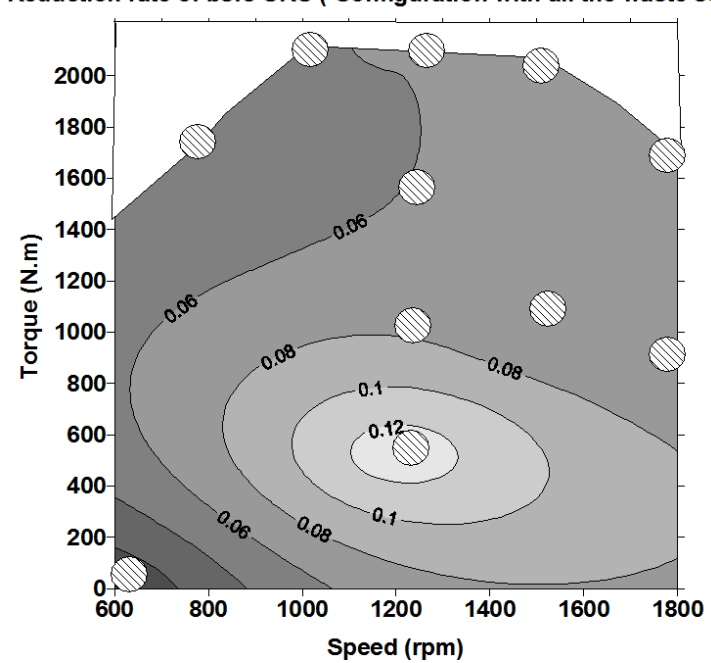

Reduction rate of bsfc RC (Configuration with all the waste sources)

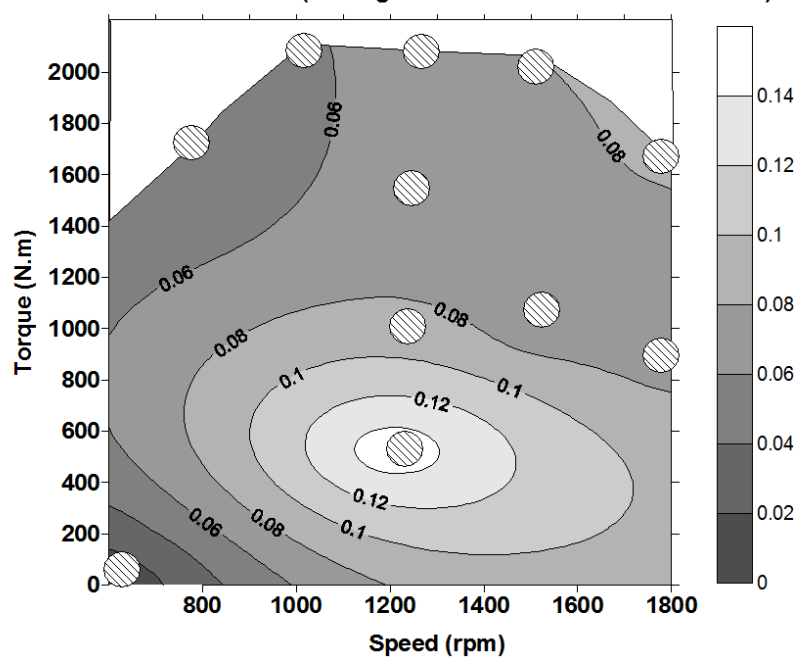

Figure 6: Reduction rate of $b s f c$ with an $\mathrm{ORC} / \mathrm{RC}$ for the configuration with all the sources configuration (case $\mathbf{A}$ ) 


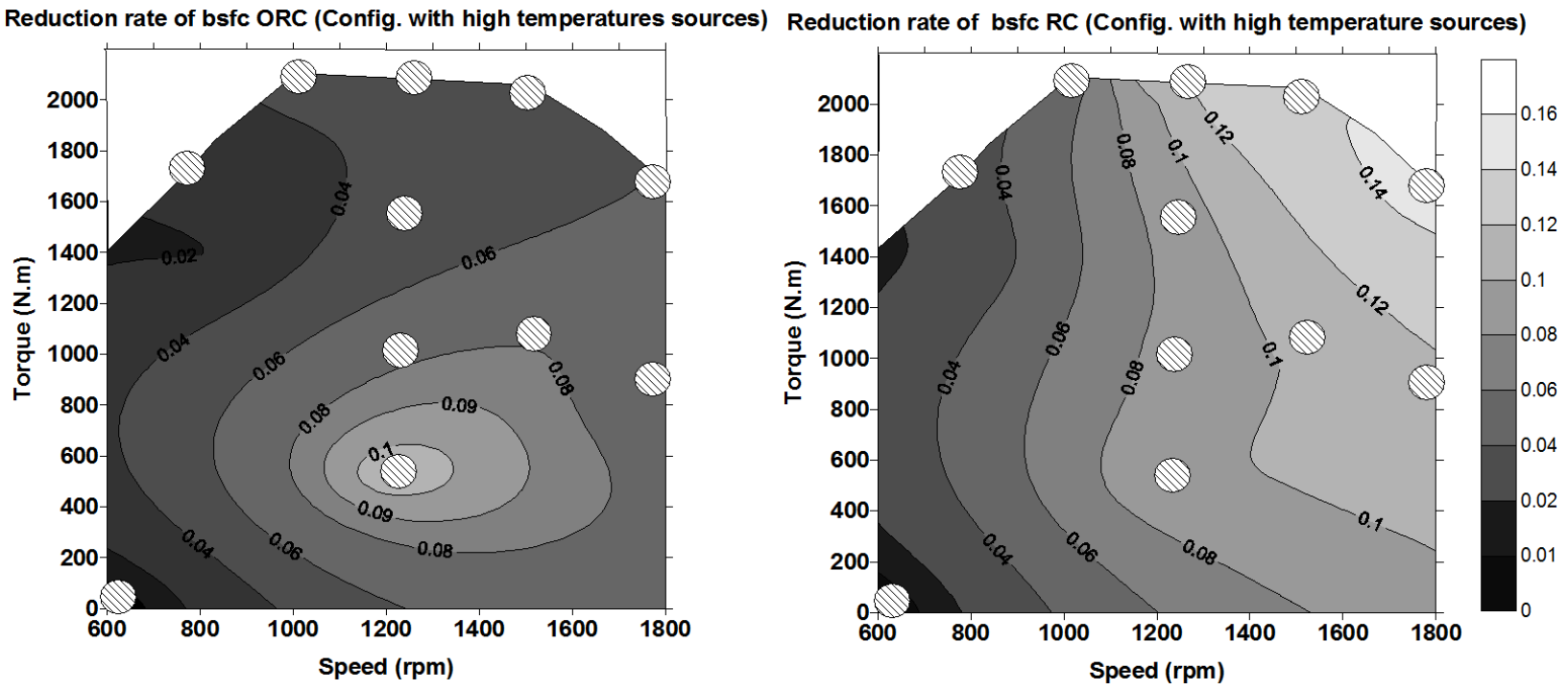

Figure 7: Reduction rate of $b s f c$ with an ORC/RC for the configuration with high temperature sources (case $\mathbf{B}$ ) 


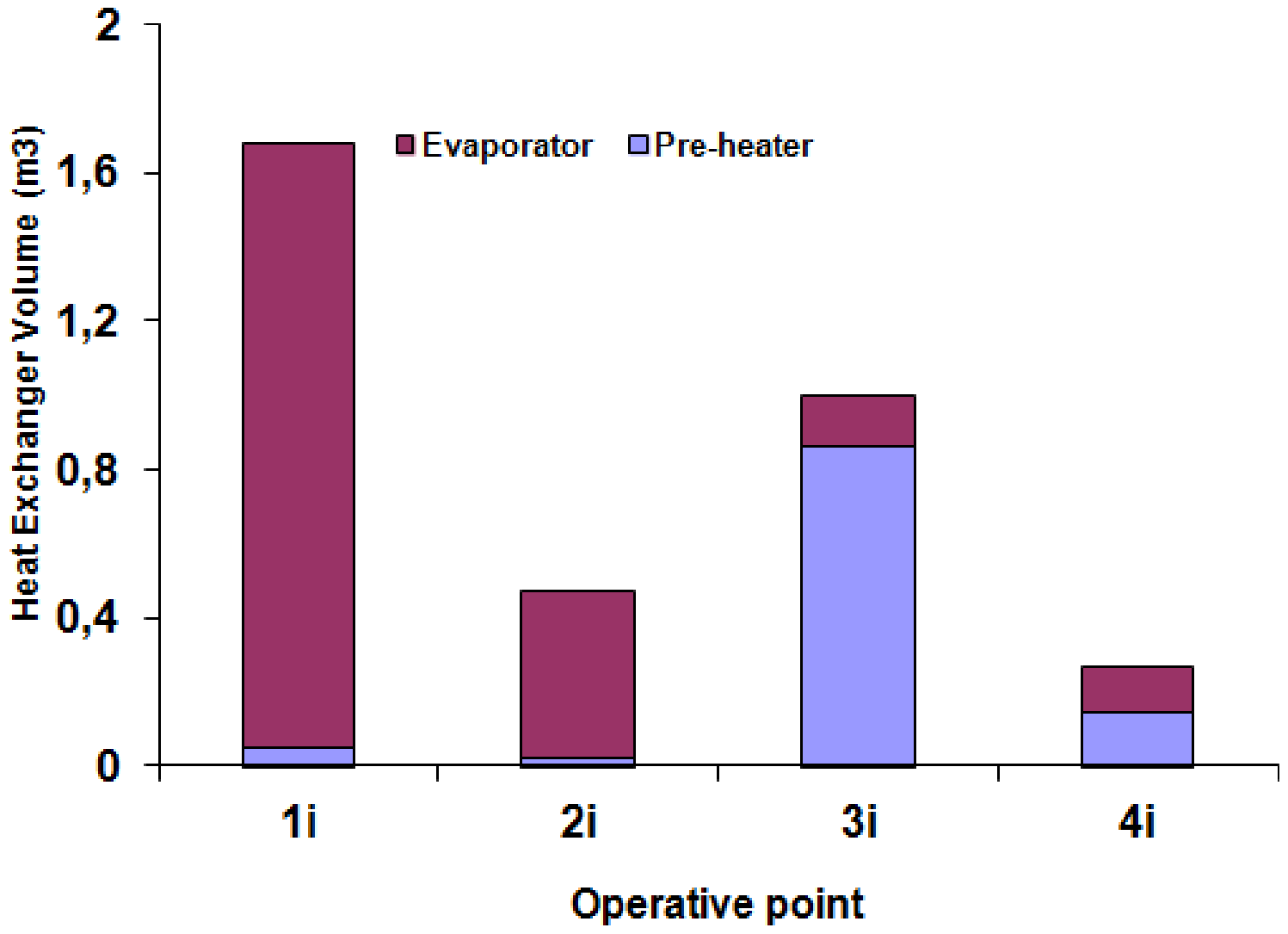

Figure 8: Volume requirements for the implementation of a bottoming cyle in four optimum operating points selected in Table 2 

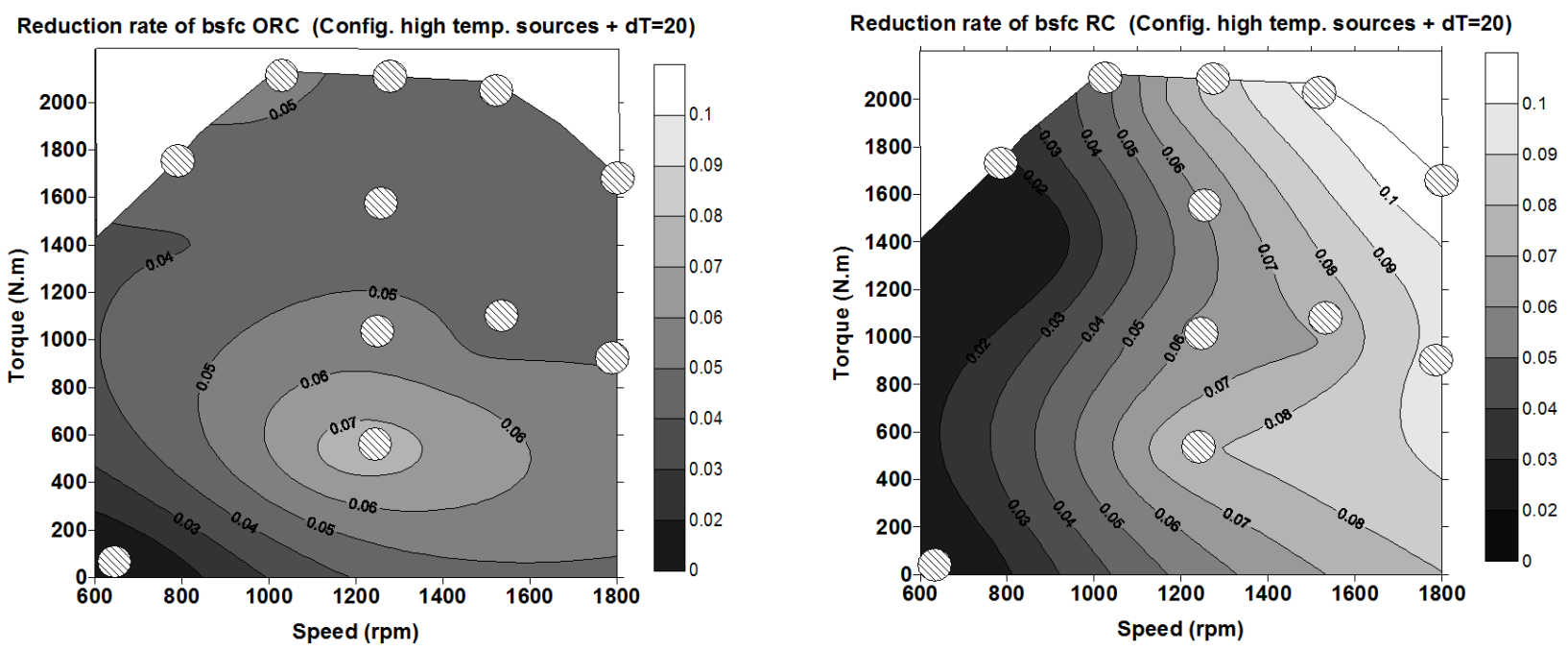

Figure 9: Reduction rate of $b s f c$ in the configuration with high temperature sources (case $\mathbf{B}, d T=20^{\circ} \mathrm{C}$ ideal cycle assumption) 


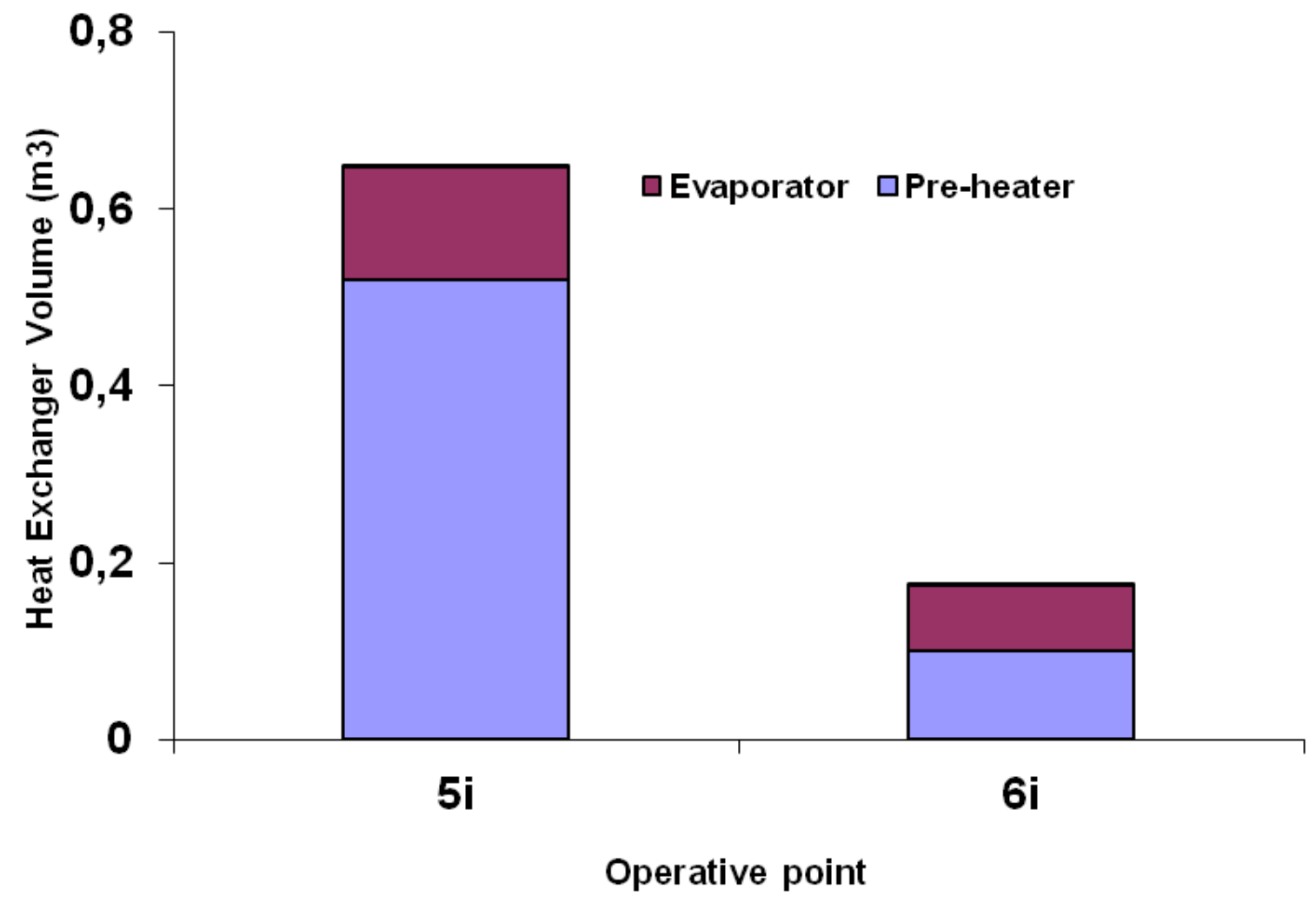

Figure 10: Volume requirements for the implementation of a bottoming cyle in two optimum operating points selected in Table 2 

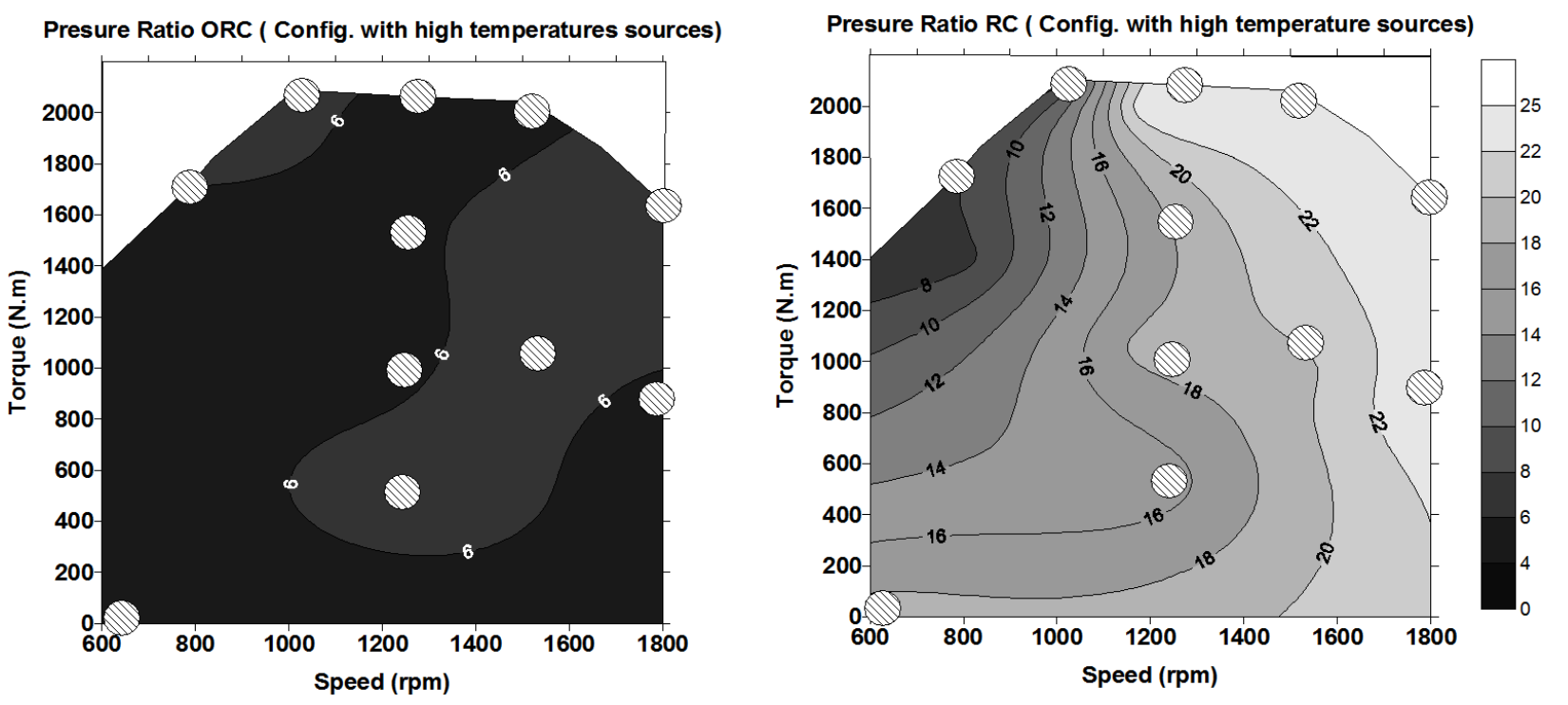

Figure 11: Expansion ratio in the expander machine for the configuration with high temperature sources (case $\mathbf{B}$ ) and $d T=10^{\circ} \mathrm{C}$ 
Reduction rate of bsfc ORC (Case $A+d T=10+$ Real Expander and pump)

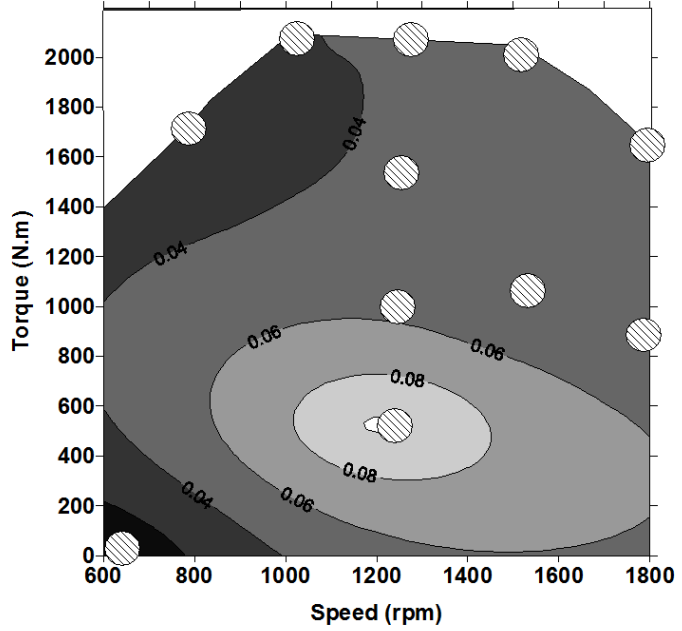

Reduction rate of bsfc ORC ( Case $B+d T=10+R e a l$ expansor and pump)

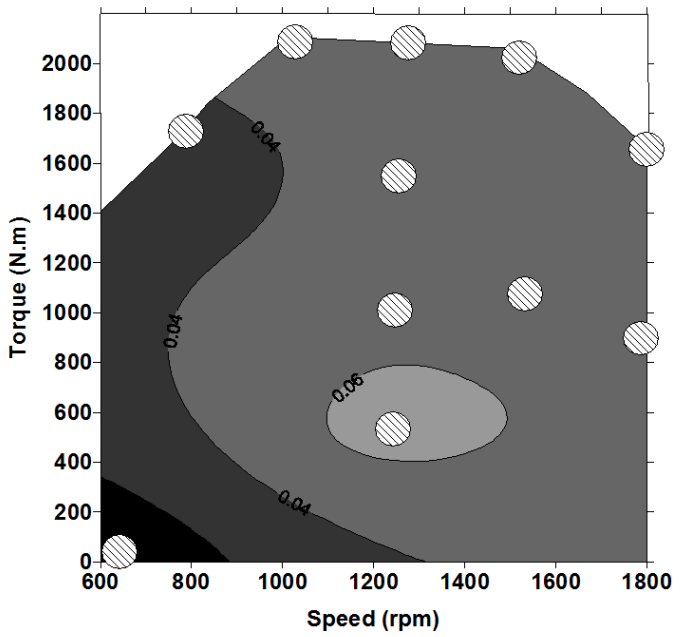

Reduction rate of bsfc RC ( Case $A+d T=10+$ Real Expander and pump)

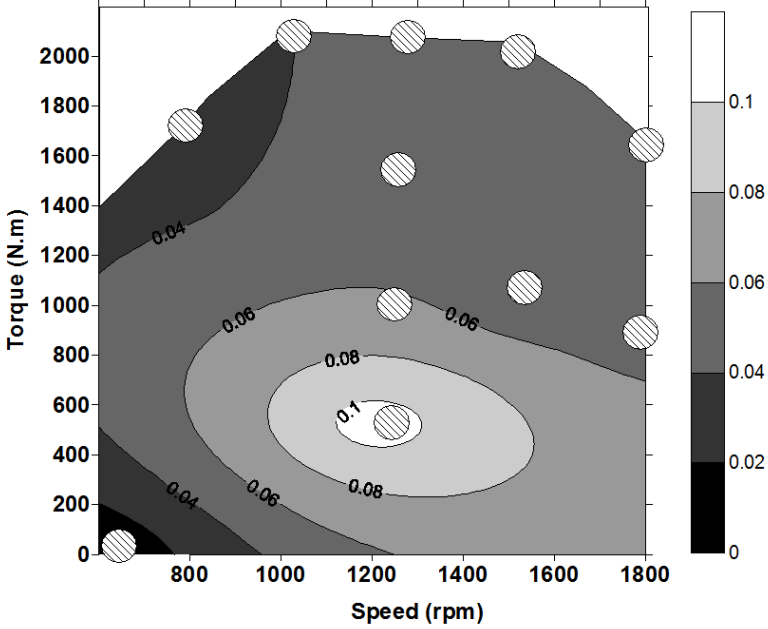

Reduction rate of bsfc RC (Case B+ $\mathrm{dT}=10$ + Real expansor and pump)

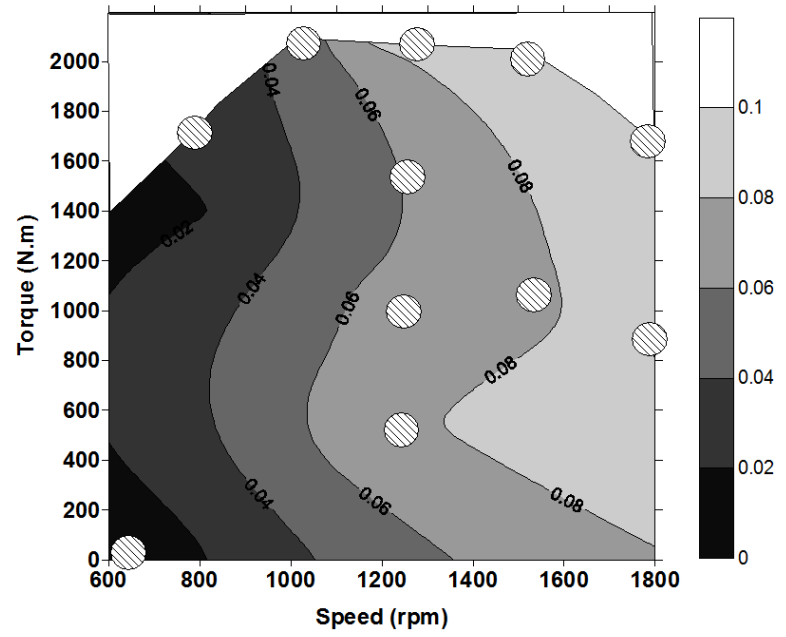

Figure 12: Reduction rate of $b s f c$ with real expander and pump with $d T=10^{\circ} \mathrm{C}$ for case $\mathbf{A}$ (Top) and case $\mathbf{B}$ (Bottom) 

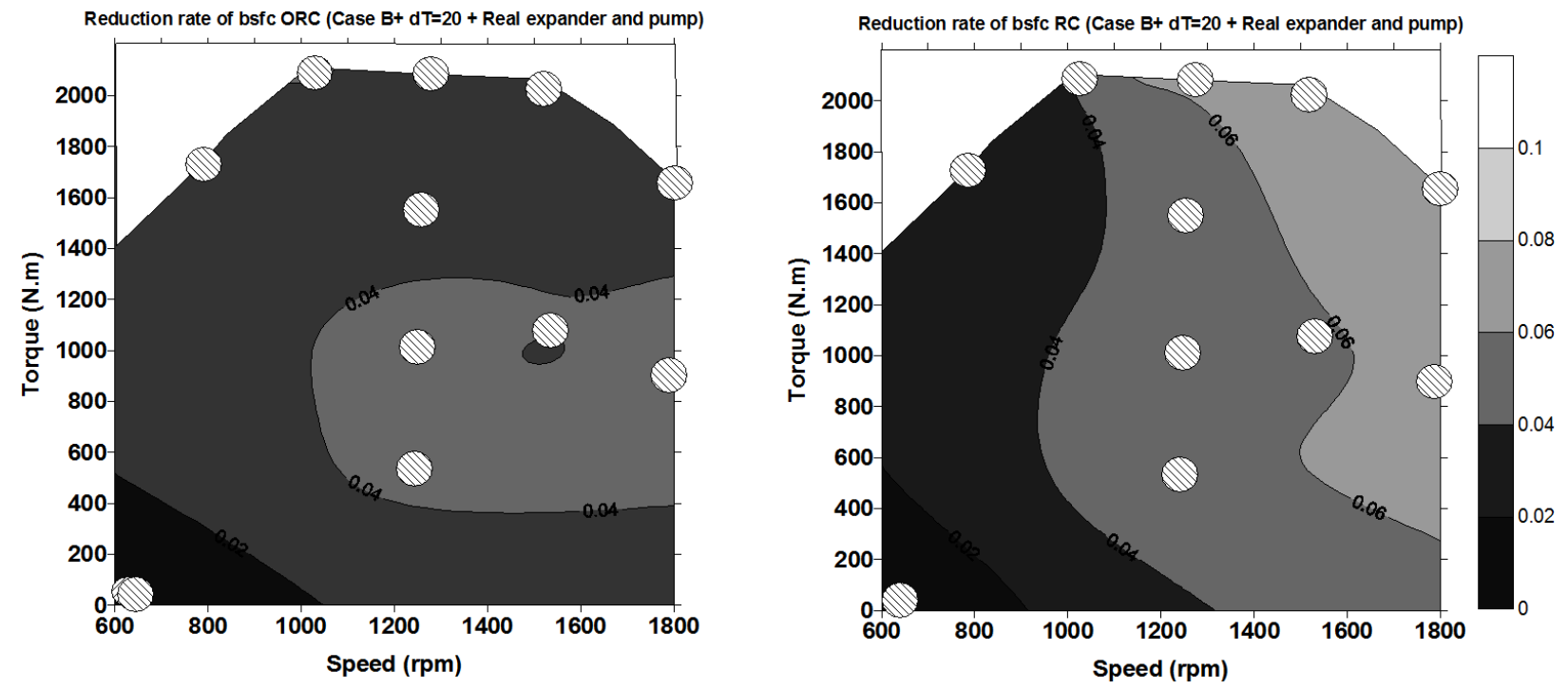

Figure 13: Reduction rate of $b s f c$ with real expander and pump with $d T=20^{\circ} \mathrm{C}$ for case $\mathbf{B}$ 